\title{
Cognitive performance and specific aspects of language processing are associated with Oldowan- like chert flaking and retouch
}

Petar Gabrić ( $\square$ petar.gabric@uni-marburg.de )

https://orcid.org/0000-0003-2644-194X

Marko Banda

Ivor Karavanić

\section{Research Article}

Keywords: neuroarchaeology, language evolution, cognitive evolution, experimental archaeology, technological hypothesis

Posted Date: December 30th, 2021

DOI: https://doi.org/10.21203/rs.3.rs-1212115/v1

License: (c) (i) This work is licensed under a Creative Commons Attribution 4.0 International License. Read Full License 


\section{Abstract}

Experimental data suggesting a co-evolutionary relationship between Palaeolithic stone toolmaking, and cognition and language remain limited to indirect findings of neurophysiological studies. Furthermore, retouch and quartz flaking remain uninvestigated. We recruited thirteen subjects and taught them to produce quartz choppers and chert sidescrapers in either a verbal or gestural condition. Two raters rated on a 5-point scale the subjects' performances on specific steps of the two stone toolmaking tasks. Subjects also performed on a neuropsychological battery encompassing visuospatial, executive functioning, and linguistic tasks. Given the small sample size, the results should be regarded as exploratory and preliminary. There was only limited evidence that verbal compared to gestural teaching facilitated acquisition. Quartz chopper manufacture was not associated with cognitive performance. Conversely, chert flaking and retouch were moderately and strongly associated with visuospatial working memory and executive functioning. Specific aspects of chert flaking were also associated with verbal fluency performance, showing, among others, moderate and strong positive associations with the productivity and rate of production of syntactically transitive verbs on action fluency. Controversially assuming similar results would have been obtained by testing extinct hominins, our results possibly suggest Oldowan hominins relied on modern-like visuospatial working memory and executive functioning during chert knapping. Furthermore, some prerequisites for aspects of action language and syntactic transitivity in modern humans might have been to some degree present in Oldowan hominin populations. We conclude by proposing that the quality of performance on Oldowan knapping may not reflect the full level of cognitive capacities of Oldowan populations.

\section{Introduction}

\subsection{Language, cognition, and Palaeolithic stone tools}

Modern humans are the only known species possessing language. Furthermore, in normal circumstances, all humans acquire at least one language before a certain developmental phase (cf. Levelt 2018; Pagel 2017). Thus, it can be hypothesized that language evolved no later than human speciation but not before the split from the last common ancestor of humans and chimpanzees. Language encompasses both the functioning of general bodily systems (breathing and digestion, musculoskeletal structures, hearing, cognition, etc.) and seemingly specific phenomena spanning from phonetics and phonology to morphology and syntax. Because language is such a multifaceted capacity, it seems plausible to hypothesize that language did not evolve in one "package", but that specific language-related capacities appeared in the hominin lineage (or sooner) at different phylogenetic stages via different sets of mutations and evolutionary processes (which may have nevertheless been somehow intertwined; cf. Arbib 2016a, 2016b; Bickerton 1990: § 5-7, 2007; Botha 2020; Casielles \& Progovac 2012; Collier et al. 2014; Dediu \& Levinson 2013, 2018; Everett 2016: § 9-11; Hauser 1921: 113-122; Gabrić 2021a, b, c, d, e, 2022; Jackendoff 1999; Jackendoff \& Wittenberg 2014; Krause et al. 2007; Lieberman 2015; McMahon \& McMahon 2013: § 8-9; Michlich 2018; Planer 2017; Progovac 2015, 2016; Révész 1946; but see Berwick et al. 2013, Berwick \& Chomsky 2016, Chomsky 2002: 161-162, Chomsky et al. 2019, Matasović 2012: 
55ff., Tattersall 2019 for different opinions). If language indeed did not evolve in one "package", it is plausible that some linguistic capacity was extant at least in the last common ancestor of modern humans and Neanderthals.

Despite these hypotheses and the recently reawakened interest in the evolution of cognition and language, hypothesis-testing research in this domain remains scarce. One controversial approach has been to identify behavioral correlates of specific cognitive functions in the archaeological and palaeoanthropological records (Bednarik 2013; Chase \& Dibble 1987; Conrad et al. 2009; Criado-Boado et al. 2019; d'Errico 2003; d'Errico et al. 1998, 2005; Davidson 2013, 2014; Frayer et al. 2020; Henshilwood \& Marean 2003; Hoffmann et al. 2018; Lindly \& Clark 1990; Majkić et al. 2018; Prévost et al. 2021; Radovčić et al. 2015; Riel-Salvatore et al. 2001; Rigaud et al. 2009; Roebroeks et al. 2012; Tuniz et al. 2012; Turk et al. 2001; Watts 2009; Zilhão et al. 2010; see Bell 1994, Botha 2009, 2010, 2012, Garofoli 2014, Garofoli \& Iliopoulos 2019 for criticisms). A large part of the research focus in this domain has been placed on Palaeolithic-stone-tool-related behaviors and it has been hypothesized by many that there might have been a co-evolutionary link between specific aspects of stone tool manufacture on the one hand, and the evolution of language and cognition on the other (Bruner et al. 2018; Davidson \& McGrew 2005; Gabrić et al. 2018, 2021a; Lycett \& Eren 2018; Moore \& Preston 2016; Muller et al. 2017; Nonaka et al. 2010; Normile 2012; Nowell \& Davidson 2010; Overmann \& Wynn 2018; Parravicini \& Pievani 2019; Stout 2010, 2011; Stout \& Chaminade 2012; Stout \& Hecht 2015; Stout \& Khreisheh 2015; Toth \& Schick 2009; Uomini 2015; Vaesen 2012; see Bar-Yosef 2017, Coolidge et al. 2015, Coolidge \& Wynn 2001, 2005, 2016, Overmann \& Coolidge 2019, Pain 2021, Wynn \& Coolidge 2011, 2016, Wynn \& Gowlett 2017 for different opinions). In other words, cognitive functions underlying linguistic capacity in modern humans - sensorimotor and visuospatial processing, working memory, declarative and procedural memory, executive functioning, cognitive planning, learning, etc. (cf. Hamrick et al. 2018) - could have been evolutionarily fine-tuned in association with the emergence or maintenance of specific stone-tool-related behaviors (e.g., manufacture and its acquisition), thus paving the way for the evolution of modern-like language (Lotem et al. 2017; Kolodny \& Edelman 2018). Theoretical discussions have thus far proposed several cognitive "common denominators" for stone-tool-related behaviors and language; namely, action observation and execution (including sequential and hierarchical action processing; Adornetti et al. 2018; Arbib 2011; Brozzoli et al. 2019; Everett 2016: 80ff.; Greenfield 1991; Mahaney 2014; Moore 2010; Osiurak et al. 2020; Ruck 2014; Schlanger 1996; Vandervert 2018, 2020; cf. Kroliczak et al. 2021), auditory working memory and attention (Putt \& Wijeakumar 2018; Vandervert 2018, 2020), social learning (Everett 2016: § 3-4; Gärdenfors \& Högberg 2017; Lotem et al. 2017; Nishiaki 2019; Tennie et al. 2017; cf. Akazawa et al. 2014; Baronchelli et al. 2012; Botha 2015; Corbey et al. 2016; Gamble et al. 2011; Gibson 2012; Gowlett et al. 2012; Hewlett 2021; Mufwene 2018; Nonaka et al. 2010; Spike 2017; Rossano 2017), visuospatial processing (Bruner et al. 2018; cf. Schween et al. 2018), executive functioning and planning (Adornetti 2014; Ambrose 2010; Barham \& Everett 2020; Everett 2016: 96-97, 112-113), etc.

Notably, a number of studies have indicated both anatomical and functional overlaps in the processing of real actions on the one hand, and action language on the other (see Arbib 2005, 2006, 2012, 2015, 2017, Arbib et al. 2014, Barsalou 2008, Frak \& Cohen 2021, Ghio \& Tettamanti 2016, Hauk et al. 2016, 
Kemmerer 2015, Pulvermüller 2013, 2018, Pulvermüller \& Fadiga 2010 for reviews; Aziz-Zadeh et al. 2006; Boeckx \& Fujita 2014; De Beni et al. 2005; Desai et al. 2010; Dreyer \& Pulvermüller 2018; Dreyer et al. 2020; Geld 2006; Gianelli et al. 2020; Glenberg \& Kaschak 2002; Grisoni et al. 2016; Hauk et al. 2004, 2006; Heard et al. 2018; Mollo et al. 2016; Progovac et al. 2018; Pulvermüller et al. 2005; Rizzolatti \& Craighero 2004; Tettamanti et al. 2005; van Dam \& Desai 2016; Willems et al. 2010; cf. Brauer et al. 2013; Hurford 2012; Kemmerer 2014). In other words, processing of action language is partly subserved by the functioning of the same brain areas and the same cognitive mechanisms which are involved in real action observation and execution. Action language refers to words and constructions which denote actions (e.g., the English verbs run, kick, play, attack, swing, dance, etc.) or other aspects of action events (e.g., agents and patients: attacker-attackee). Because Palaeolithic stone toolmaking is essentially a goal-directed action, it is plausible to hypothesize that there should be a positive association between behaviors related to stone toolmaking and action language use in modern humans. If this is so, a possible, yet controversial, evolutionary hypothesis would be that specific cognitive aspects of real action processing in the context of Palaeolithic stone toolmaking were evolutionarily reused for (action) language evolution.

Most studies investigating the relationship between real action and action language processing have focused on semantically transitive events and constructions. Semantically transitive constructions denote events in which an agent performs an action on a patient, with the latter experiencing some kind of transformation. Some English-language examples of semantically transitive verbs include break (e.g., He broke the glass.), cut, kill, hit, strike, kick, move, push, eat, take, etc. On the other hand, syntactically transitive verbs are verbs that are coded in terms of a subject and direct object and they do not have to be semantically transitive (e.g., I see a tree., She feels love., They crossed the street., She ran one hour., etc.; All of the four examples express semantically intransitive events.) (Creissels 2016; Fotiadou \& Vassiliadou 2017; Saeed 1997: § 3.6, 6.1-6.6; cf. Palmer et al. 2010: § 1; Petruck 1996; Wright 2002).

The processing of semantically transitive verbs has been, among other areas, associated with increased metabolic activity in the pars opercularis of Broca's area (Kemmerer 2012; Tettamanti et al. 2005; cf. Chen et al. 2021). While neural and cognitive correlates of syntactic transitivity are not well understood, some studies which investigated the processing of more elaborate transitive coding frames (such as those involving dependent object clauses) have found increased metabolic activity and/or structural integrity of the left pars triangularis of Broca's area (Tyler et al. 2011; cf. Casado et al. 2020; Maran et al. 2021; van Dam \& Desai 2016). Some have also hypothesized that because the supposed roles of the pars opercularis include, among others, representing actions at the conceptual level and representing the sequential and hierarchical organization of action concepts [i.e., agent-action(-instrument, patient, etc.)], there might have been a phylogenetic stage in which pars opercularis, or perhaps pars triangularis, applied these conceptual, sequential, and hierarchical processes via schematization to other cognitive domains, including more elaborate actions as well as language (Christensen 2010; Fazio et al. 2009; Fiebach et al. 2006; Gabrić 2021c, e: § 3; Kemmerer 2012; Kunert et al. 2015; Ruck 2014; cf. Ardila et al. 2016; Cohn et al. 2017; Cohn \& Paczynski 2013; Fadiga et al. 2009; Foundas et al. 1996; Ghio \& Tettamanti 2016; Grodzinsky 2000; Hopkins et al. 2017; Hupfeld et al. 2017; Liuzzi et al. 2017; Novén et 
al. 2019; Tate et al. 2014). Presumably, striking a core is cognitively processed as a semantically transitive event because an agent (knapper) performs an action (striking with a hammer) on a patient (core) and so changes the patient (core reduction). It is nevertheless possible that some level of action schematization is needed for the acquisition and execution of Palaeolithic stone toolmaking in modern humans, given that some have argued that action schematization is essential for the execution of at least some forms of Palaeolithic stone toolmaking (Herzlinger et al. 2017; Moore 2010; Schlanger 1996; Shimelmitz \& Kuhn 2018; Sumner 2011) and that Hecht et al. (2014) reported that a two-year-long acquisition of Palaeolithic stone toolmaking was associated with fractional anisotropy changes in the pars triangularis. Thus, depending on the level of schematization of the actions involved in the acquisition and execution of Palaeolithic stone toolmaking, modern humans might show a positive relationship between the behaviors related to Palaeolithic stone toolmaking on the one hand, and either semantic or syntactic transitive language use (or both) on the other.

\subsection{Oldowan}

Oldowan is the earliest well-defined stage of hominin stone technology, ranging from 2.6 (Semaw 2000, 2006; Semaw et al. 1997, 2003) to 1.4 (Schick \& Toth 2006; Toth \& Schick 2018) or 1.26 Ma (Semaw et al. 2020). The putatively earliest stone tools from Lomekwi, Kenya, putatively displaying simpler knapping techniques, have been dated to 3.3 Ma (Harmand et al. 2015; Hovers 2015), yet their status remains disputed (Domínguez-Rodrigo \& Alcalá 2016; but see Harmand et al. 2019 for a response to some of the criticisms), while Toth \& Schick (2018: 7) list the artifacts from Lomekwi as part of the "Oldowan Industrial Complex". Oldowan stone tool assemblages are typically characterized by the predominance of flaked core tools, namely unifacial choppers and bifacial chopping tools, flakes and other debitage, and battered percussors (Schick \& Toth 2006). The majority of the knapping was done through hard-hammer percussion, either direct or bipolar, but the use of both the anvil technique and throwing against a hard substrate have also been proposed (Schick \& Toth 2006). While some choppers and chopping tools may have been used for carcass processing (bone splitting and pounding) and other tasks, many such objects were possibly only cores (Shea 2020; Toth 1985). Regardless of their functional status, the knapping of these core tools and other core forms produced sharp-edged flakes which had the potential for use in butchering (Toth 1985, 1987). Retouched flake tools also appear in Oldowan assemblages along with unretouched flakes, although they are not ubiquitous or numerous (Schick \& Toth 2006). Oldowan is primarily associated with the early Homo members (H. habilis and $H$. erectus), yet the contemporaneity of Australopithecus garhi occupation and animal bones displaying traces of breaking and cutting at Bouri, Ethiopia (de Heinzelin et al. 1999), with the stone tools in Gona suggest the possibility that $A$. garhi produced Oldowan stone tools as well (Semaw 2000; Semaw et al. 1997, 2005; cf. Schick \& Toth 2006; Toth \& Schick 2018). Furthermore, marks on bones found at the Dikika site, Ethiopia, strongly suggest that this behavior can also be attributed to Australopithecus afarensis (McPherron et al. 2010) and it is also possible that Paranthropus was one of the Oldowan tool makers (Susman 1991). Toth and Schick (2018) argued that Oldowan findings are suggestive of the incorporation of stone tools as a critical adaptive component which presumably led to more complex subsistence strategies, social behavior, and communication, while Michlich (2018) proposed based on an extensive review that 
Australopithecus africanus was capable of indexical, iconic, and possibly symbolic communication ("symbolic" in the semiotic, and, by extension, linguistic, i.e., Peircean and Saussurean sense and not in the sense of "symbolic" or "modern" behavior which is axiomatically inferred from artifacts and behaviors such as pigment use, personal ornaments, funerary practices, etc.; cf. Botha 2020).

Oldowan knapping behaviors display a degree of variation through time and space, and there has been a heated debate on whether there have been technological, cognitive, or different leaps within the Oldowan or if the variations in Oldowan knapping behaviors can be explained by environmental factors. One of the earliest proposals that there were technological leaps within Oldowan in the Olduvai Gorge was put forward by Leakey $(1971,1975)$ who differentiated between the so-called Classic Oldowan and Developed Oldowan A (DOA), with the latter supposedly associated with lower rates of choppers and increased rates of proto-bifaces, spheroids, subspheroids, and light-duty tools compared to the former. Following a similar line of thinking, Ludwig (1999) argued that the increased use of chert and increased manufacture of quartz spheroids and subspheroids during the DOA reflected enhanced knowledge of knapping mechanics and raw material selection, while de Lumley et al. (2009) proposed that some Oldowan sites older than 1.9 Ma such as Gona, Lokalalei, and Fejej should be regarded as "PreOldowan" because they display, among other putatively distinctive features, markedly high proportions of simple core tools and only sporadic retouch.

However, other research has suggested that these phenomena are best explained by raw material availability. Lithic analyses of the Bed I and II assemblages from Olduvai Gorge have convincingly shown that the incorporation of chert for stone tool manufacture in the Bed II Oldowan (1.65-1.53 Ma), when chert became available, elicited a considerable decrease in quartz and lava knapping and a considerable increase in chert knapping compared to the Bed I Oldowan (1.87-1.75 Ma), which turned back to Bed I Oldowan levels after chert became unavailable again (Kimura 1997, 1999, 2002; de la Torre \& Mora 2014; McHenry \& de la Torre 2018). Also, retouch was only limitedly present in the quartz and non-existent in the lava assemblages but was highly present in the chert assemblages (cf. de la Torre \& Mora 2018). Chert was available at several locations in the Olduvai Gorge only during specific periods when the palaeolake Olduvai would retreat due to fluctuations in geological phenomena, exposing chert beds on the surface (Kimura 2002; McHenry \& de la Torre 2018; cf. Stiles et al. 1974). The higher rates of flaking and retouch in chert-associated periods most likely reflect the fact that chert's fine-grained texture makes it more suitable for both flaking and retouch compared to quartz and lava (Kimura 2002; McHenry \& de la Torre 2018; cf. Spott 2005), indicating that the observed changes in knapping behaviors should be attributed to chert availability, rather than anatomical, cognitive, cultural, or other adaptations in the hominin populations (cf. Proffitt 2018). Furthermore, intersite variations in chert knapping behaviors have been explained either by chert availability or by differences in the locations on which different stages of the core reduction process took effect (Kimura 2002; but see Braun et al. 2005 for the latter). Thus, it would appear that the hominin populations which had access to chert were somehow anatomically, cognitively, culturally, and/or differently ready to incorporate it into their knapping behavior repertoire and adjust the repertoire. Interestingly, McHenry \& de la Torre (2018) write that these hominins were "aware of the better flaking qualities" of chert compared to quartz and lava. Additionally, the putatively novel 
manufacture of quartz spheroids and subspherioids had in fact already been documented at pre-Olduvai Oldowan sites and discrepancies in the rates of quartz spheroid and subspheroid manufacture across place and time have been explained by differences in raw material availability as well (Semaw et al. 2009; cf. Sahnouni 2002; Sahnouni et al. 1997; Sahnouni \& de Heinzelin 1998; Willoughby 1985).

Still, some Oldowan sites paint a slightly more complex, yet enigmatic, picture. Lithic analyses of the assemblages at HWK EE, a late Oldowan site dated to $1.7 \mathrm{Ma}$, have demonstrated that knapping behaviors were characterized by shorter reduction sequences, lower flaking productivity, and simpler knapping methods compared to other Oldowan sites: "HWK EE hominins seem to have been uninterested and/or unable to exploit [quartz, lava, and chert] cores intensively and, if we are to use modern standards of productivity and efficiency, both were generally very low." (de la Torre \& Mora 2018; cf. Arroyo \& de la Torre 2018; de la Torre et al. 2018; McHenry \& de la Torre 2018; Pante \& de la Torre 2018). It is thus possible that there were hominin populations in the Olduvai Gorge which displayed lower levels of either capacity or preference for more extensive stone-toolmaking-related behaviors, independently of the raw material type.

\subsection{Previous experimental studies}

Experimental studies of the putative co-evolution between stone-tool-related behaviors and language are found few and far between, probably due to serious methodological limitations. Many issues are epistemological, including the fact that the cognition of extinct hominin species cannot be directly assessed and valid model organisms for these species are currently non-existent (cf. Breyl 2020; Michlich 2018: 7; Putt et al. 2017: 1; but see Dannemann et al. 2020; Trujillo et al. 2021). Fortunately, however, the small number of previous experimental studies provide a valuable, albeit only fragmentary picture of how Palaeolithic-stone-tool-related behaviors are associated with modern brain and cognitive functioning. These studies can be tentatively divided into (1) teaching mode studies and (2) neuroimaging studies.

Teaching mode studies have mainly been trying to determine which modes of teaching, i.e., modes of transmission of information about stone tool manufacture in a teaching-learning context, can facilitate the acquisition of different stone-tool-related behaviors. Morgan et al. (2015) found that the acquisition of Oldowan-like chert flaking was facilitated in the gestural and verbal teaching conditions compared to imitation. Similar results have been obtained by Lombao et al. (2017) who investigated the acquisition of the alternating method applied on commercial bricks. However, Cataldo et al. (2018) found that Oldowanlike chert flaking was significantly better in the gestural and verbal teaching conditions compared to the (rather unnatural) gesture-free verbal teaching condition, possibly indicating that it is the gestures rather than spoken language alone that have a facilitatory effect on Oldowan-like (chert) flaking acquisition. Interestingly, contrary to the expectation that the acquisition of later stone technologies should then also be facilitated by either gestural or verbal teaching, Ohnuma et al. (1997) found no significant differences between the verbal and nonverbal teaching conditions in the acquisition of Levallois flaking on siliceous shale, while Putt et al. (2014) found that the verbal condition was associated with significantly worse chert flake quality during Acheulean-like biface manufacture compared to imitation. 
Hecht et al. (2014) conducted a longitudinal diffusion tensor imaging study in which subjects spent two years acquiring Oldowan-like flaking, Acheulean-like biface manufacture, and Levallois flaking. Fractional anisotropy changes were observed in the left supramarginal and ventral precentral gyri, and the right pars triangularis (part of Broca's area), indicating that the acquisition of the three Palaeolithic behaviors is associated with structural remodeling of inferior frontoparietal areas. In three studies using different neurophysiological techniques, it was found that Oldowan-like flaking compared to baseline is associated with increased metabolic activity in the cerebellum, secondary motor areas, and parietal areas, but not in the prefrontal cortex, tentatively suggesting that Oldowan-like flaking and its acquisition are not particularly executively demanding (Putt et al. 2017; Stout et al. 2000; Stout \& Chaminade 2007). On the other hand, the acquisition of Acheulean-like biface manufacture relative to Oldowan-like flaking was associated with increased metabolic activity in inferior prefrontal (including the right Broca's area), frontal, and parietal areas (Stout et al. 2008; cf. Putt et al. 2017). Putt et al. (2017) suggested that the association between metabolic activity in Broca's area and Acheulean biface manufacture acquisition is limited to verbal teaching contexts, calling into question the role of Broca's area in previous studies of Palaeolithic-stone-tool-related behaviors (cf. Bourguignon et al. 2018). However, these interpretations have been criticized (Gabrić et al. 2018: 14, 2021a; Uomini 2017). Be that as it may, because Broca's area has a role in, among others, conceptual and schematic body representation, sequential and hierarchical goal-directed action processing, and aspects of linguistic and speech processing, it has been hypothesized that Broca's area might have been a point of convergence in the evolution of language and stone-tool-related behaviors (Ruck 2014; cf. Kemmerer 2012; Rosenzopf et al. 2020). Increased metabolic activity in the prefrontal cortex during Acheulean-like biface manufacture compared to Oldowan-like flaking was not observed in expert knappers (Stout et al. 2008; cf. Stout et al. 2011), suggesting it is associated with acquisition rather than pure execution.

Converging data suggest that Acheulean-like biface manufacture may be more cognitively demanding than Oldowan-like flaking, with Oldowan-like flaking being apparently largely reliant on sensorimotor processing. Nevertheless, the involvement of the cerebellum and parietal areas might suggest an association with other cognitive functions as well. It is important to note that different parts of the cerebellum are related to both linguistic and speech processing (Mariën et al. 2014), attention (Kellermann et al. 2012), emotional control (Adamaszek et al. 2017), etc., while the parietal lobe, although known to be a seat of various functions (including linguistic and action processing; Bzdok et al. 2016; Deschamps et al. 2014; Fagg \& Arbib 1998; McDowell et al. 2018; cf. Numssen et al. 2021), is likely functionally the least understood lobe. Furthermore, both the parietal cortex (Bruner et al. 2010) and cerebellum (Kochiyama et al. 2018; cf. Miura et al. 2014) have witnessed significant changes in size during hominin evolution. It is also very important to note that it is epistemologically problematic to infer cognitive processes from neuroimaging data (Poldrack 2006), especially of such broadly demarcated brain areas as in these studies. In fact, these areas are all associated with performances on tasks tapping into various cognitive capacities, suggesting that a more direct method is needed to establish a preliminary association between stone-tool-related behaviors and cognition. 
The only experimental study thus far to compare neuroimaging data during a stone-tool-related behavior and performance on a cognitive task was by Uomini \& Meyer (2013) who reported from their functional transcranial Doppler ultrasonography study with expert knappers high correlations between the hemodynamic lateralization patterns during Acheulean-like biface manufacture and silent letter fluency (naming as many words starting with a given letter), indicating similar patterns in the functional lateralization of particular linguistic functions and Acheulean-like biface manufacture (cf. Jöris \& Uomini 2019; Osuna-Mascaró et al. 2020; Steele \& Uomini 2009; Uomini 2015; Uomini \& Ruck 2018; Vigneau et al. 2011).

In the present study, the aims were to (1) investigate the role of verbal and nonverbal teaching-learning contexts on the early acquisition of Oldowan-like quartz flaking, and chert flaking and retouch, (2) investigate the neuropsychological correlates of the early acquisition of specific technological steps during Oldowan-like flaking and retouch, and (3) specifically investigate possible associations between action language and Palaeolithic stone toolmaking. We were motivated by (1) the prevalence of use of chert as raw material in experimental studies (compared to, e.g., quartz), (2) lack of studies directly investigating which cognitive functions are associated with Palaeolithic stone toolmaking in modern humans, (3) the lack of experimental studies on retouch, as all have thus far focused on flaking, and (4) lack of studies on specific steps of the production process, as all have thus far focused on assessments of end products leaving open the question whether the observed processes are attributable to flaking in general or to some of its specific aspects. In this study, naïve subjects acquired to produce quartz choppers and chert sidescrapers in either a verbal or nonverbal condition. To explore the relationship between the performances on the stone toolmaking tasks and cognition, the subjects also performed on a battery of neuropsychological tests, assessing visuospatial working memory, cognitive planning, cognitive flexibility, and specific aspects of linguistic processing.

\section{Methodology \\ 2.1. Subjects}

Thirteen subjects were recruited for the study ( 5 males; mean age $22.69 \pm 2.43$ ). All were native speakers of Croatian dialects, fluent in Standard Croatian, students at the University of Zagreb, young adults, and right-handed as assessed by the Edinburgh Handedness Inventory (Oldfield 1971). Further exclusion criteria included experience in archaeology, self-reported history of psychiatric or neurological disorders, impaired manual dexterity, and uncorrected vision impairment. Subjects were allocated into verbal or nonverbal (i.e., gestural) conditions in a randomized matched-pairs design according to their rankings on the Trail Making Test (see $\S 2.4$.) while maintaining a similar male-to-female ratio. It is supposed that performance on the Trail Making Test reflects processes of visual attention (Test A) and cognitive flexibility (Test B) (Piper et al. 2012), two cognitive functions for which we a priori assumed were crucial for the acquisition of Palaeolithic stone toolmaking. Ethical approval was obtained from the "Etičko povjerenstvo za znanstveno-istraživački rad" of the Faculty of Humanities and Social Sciences, University 
of Zagreb (dated 2018/10/03). All subjects signed an informed consent form and were aware of the goals of the study.

\subsection{Stone toolmaking tasks}

All subjects first performed on a neuropsychological battery (except the letter fluency task). All neuropsychological assessments were conducted on the same day and all subjects were assessed within ten days. One to two weeks thereafter the subjects performed on the stone toolmaking part of the experiment in groups of several individuals (maximally five). The stone toolmaking experiment consisted of two sessions which were divided into three phases: (1) demonstration by an experienced knapper, (2) assisted practice, and (3) task. Lastly, a brief post-experimental interview took place. In the first session, subjects learned to manufacture a quartz chopper, while in the second they learned to manufacture chert sidescrapers. Chopper was selected as it is one of the earliest stone tools and is frequent on Oldowan sites (Toth \& Schick 2018), while the sidescraper was selected as it represents a retouched flake tool and the specific type is found on some Oldowan sites (de la Torre \& Mora 2018; cf. Toth \& Schick 2018). The raw material type was selected based on the literature review presented in the first part of the paper.

A chopper is a core tool made on a pebble. It is produced by sequentially removing at least two flakes from only one side of the pebble, thus generating an area of connected flake negatives which makes a more-or-less sharp angle with the cortical surface of the pebble. A sidescraper is a unifacially retouched flake tool with at least one continuously retouched edge. The angle of the edge can vary from flat to abrupt and can be either straight, convex, or concave. Although sidescrapers are usually associated and more common in post-Oldowan technocomplexes (Banda \& Karavanić 2019; de Lombera-Hermida et al. 2020; Derevianko et al. 2017; Groucutt et al. 2015; Karavanić et al. 2018, 2021; Zaidner et al. 2018), we use the sidescraper from this task as a model for retouched tools in general (cf. Inizan et al. 1999). Examples of tools made by the subjects are shown in Figure 1.

The demonstrator was one of the authors (IK), a Palaeolithic archaeology professor at the University of Zagreb, experienced knapper with basic knowledge of diverse knapping techniques, approximately 30 years of experience in academic teaching, male, in his 50 s, and right-handed. During the two demonstrations, the demonstrator presented the production of stone tools by making two finite products from the same raw material collection that was to be used for the subjects, repeating two times all steps included in the productions of the two stone tools.

In the verbal condition, no constraints were placed on communication between the demonstrator(s) and subjects during the demonstration and assisted practice. Verbal instruction was given in Standard Croatian. In the gestural (i.e., nonverbal) condition, the demonstrator wasn't allowed to speak but was allowed to use mimics and gestures, including, e.g., finger-pointing, nodding, or iconic gestures (placing the ends of the palms together to convey an angle of 90 degrees), etc. Subjects in the nonverbal group were informed before the experiment that they will learn how to make two types of stone tools, but that neither the demonstrator nor the subjects were allowed to speak. They were further informed of all the experimental phases to avoid confusion. 
During assisted practice, the subjects were given raw materials to practice stone toolmaking in the presence of two demonstrators (authors IK and MB). MB is a Ph.D. candidate in Prehistoric Archaeology at the University of Zagreb, with approximately 2 years of experience in knapping (at the time of the experiment), no teaching experience, male, in his 20s, and left-handed. They were allowed to establish communication with the demonstrators and the demonstrators would also spontaneously address the subjects either to approve of what they are doing during practice or to assist them if they perceived someone needed guidance. Assisted practice lasted approximately 20 minutes. For the actual task, subjects were given a core and then instructed to choose a large hammer (and a small hammer for retouch) and to produce the stone tool(s). In the chopper task, subjects were instructed to produce one chopper (and thus two flakes), while in the sidescraper task they were instructed to produce three sidescrapers (and thus three flakes). This information was verbally transmitted to the subjects in the nonverbal group before task commencement (in a less explicit form). There was no formal constraint on time for the two tasks.

Subjects were sat on wooden chairs in a quiet room with access to sunlight. The chairs were aligned so that the demonstrator was facing the group of subjects. The subjects' chairs were arranged in an arcshaped form, ensuring that all subjects had similar access to the stimuli. All subjects were offered safety goggles and gloves to avoid eye and hand injuries. All experimental phases were videotaped for analyses using Sony A7 and Nikon D5100 video cameras, while the post-experimental interview was audiotaped for analyses. All cores and debitage were bagged individually for each subject throughout the experiment.

Behavioral data were acquired from video analyses and material assessments. Two raters (IK and MB) rated on a 5-point scale the subjects' performances on the two tasks, as well as specific steps of the production process that were taught during the demonstration and assisted practice, with 1 indicating poor performance and 5 representing the best performances within the sample. Variables for both tasks included, in the order of the production steps they represent, (1) selection of the striking platform, (2) strike quality, (3) flake quality, and (4) tool (chopper or sidescraper) quality. Additionally, (5) working edge selection, (6) working edge utilization (how well the spatial potential for retouch on the selected working edge was used), and (7) retouch quality were assessed for the sidescraper task. In the chopper task, a mean across two flaking events and two raters was calculated, while in the sidescraper task a mean across three flaking and retouch events, and two raters was computed. For both of the tasks we also categorically assessed (9) whether the subjects successfully manufactured the stone tool(s), as well as measuring (10) the raw number of strikes during flaking. We also measured morphometric attributes of the tools, but these analyses are not reported in this paper due to their complexity. For the chopper task, we measured negative, chopper, and working edge lengths, as well as pebble perimeter and working edge angle. For the sidescraper task, we measured flake length and width, core face length at the location of the flaking, flaking and retouch angles, as well as retouch and working edge lengths. Data for strike quality and the number of strikes in both tasks from one subject in the verbal group were not recorded because an object was blocking the view of the subject in the video recordings which was discovered after the task had finished. 
The post-experimental interview was conducted in a separate room immediately after the subject reported finishing the sidescraper task. Subjects were asked which stone toolmaking aspects they preferred, i.e., found most easy and most difficult.

\subsection{Materials}

Approximately 55 quartz pebbles and 17 chert cores were acquired from two sites in Croatia and personal collections of the authors. Approximately 30 of the pebbles were used as large and small hard hammers, while the rest was used as cores for choppers. Large hammers were given for flaking in both the chopper and sidescraper parts of the experiment, while small hammers were given for retouch in the sidescraper session. Chert cores were used as cores for sidescraper production. Quartz pebbles were given to subjects without prior modifications, while chert cores were adjusted by MB before the experiment for the nonexperienced learners. Adjustments included cortex removal, as well as flaking to eliminate planes of weaknesses or internal fractures and to morphologically assimilate the cores with one another.

Quartz pebbles were selected according to their morphology and overall size. Flat pebbles of generally oval or round shape were selected for chopper cores. We also took care not to use too thin pebbles, which we judged had a greater chance of perpendicular, and thus dissatisfactory, fracture. For large hammers, we selected mainly globular pebbles whose weight we judged was enough to knap other quartz pebbles and the chert cores. Smaller hammers were selected according to how well they could be held in the hand. This criterion was likewise used for the larger pebbles (hammers and chopper cores).

\subsection{Neuropsychological assessment}

We administered verbal fluency and selected tasks from the Psychology Experiment Building Language (PEBL, Version 2.0), a freely downloadable, open-source software offering a battery of computerized neuropsychological tests (Mueller 2012; Mueller \& Piper 2014). PEBL tests were conducted using visual stimuli on a personal computer equipped with a wireless mouse and keyboard for responses. In the verbal fluency tasks, stimuli (i.e., cues) were presented aurally, while the subjects were to respond vocally.

Detailed descriptions of the tests used in the study can be found elsewhere (e.g., Piper et al. 2012, 2016). Screenshots from the individual PEBL tasks are displayed in Figure 2.

Verbal fluency (VF) - Subjects performed on action (AF; What can one do at home?) and letter fluency tasks (LF; letter $\langle\mathrm{m}\rangle$, equivalent to the phoneme /m/ in Croatian dialects). On LF, subjects were simply

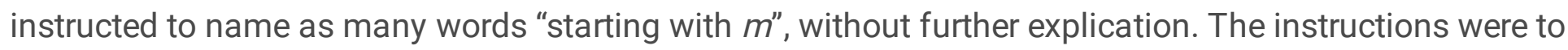
name as many words in 60 seconds per task according to the given cue. LF was administered after the post-experimental interview. Subjects' responses were audiotaped. The audio recordings were transcribed using the annotation tool ELAN (Version 5.8) (ELAN 2019; Wittenburg et al. 2006). Productivity (the raw number of legal words) was analyzed as in Gabrić \& Vandek (2021a). Clustering and switching on LF output were analyzed according to Troyer et al. (1997). On LF, clusters were defined as at least two successive words sharing the incipient or ending consonant-vowel structure (e.g., more- mostmogućnost 'sea-bridge-possibility'). We are not aware of any conventions for clustering and switching analyses in AF, so these analyses were designed a posteriori for AF. The analyses of LF and AF are 
visually summarized in Figure 3. Neurocognitive correlates underlying VF remain somewhat unclear, but it is often used for assessing prefrontal functions and is believed to at least partly reflect working memory and executive functioning (Amunts et al. 2020). From a linguistic perspective, verbal fluency incorporates lexical access and selection of both semantic as well as phonemic/orthographic representations. Dependent variables from the VF task included (1) productivity (the raw number of legal words) and (2) cluster size for each task. Because Croatian speakers (spontaneously) produce only verbs and verb-object phrases (in the neutral infinitive form) on AF, we also calculated (3) the rate of the production of semantically transitive verbs (following Barić et al. 2005: 432-435) and (4) the rate of the production of syntactically transitive verbs. Three 15 -second practice trials were conducted for all three types of VF tasks.

PEBL Lexical Decision Task (LD) - Subjects were to decide whether the presented stimulus is a word or not by pressing a key. The stimuli set consisted of 40 words and 40 phonotactically legal pseudowords (80 trials) which were presented one at a time, with a fixation cross appearing after each stimulus (delay $500 \mathrm{~ms}$ ). Word stimuli consisted of 20 highly concrete words (mean concreteness $\geq 4$, assessed on a five-point scale; e.g., olovka 'pencil') and 20 highly abstract words (mean concreteness $\leq 2$; e.g., mišljenje 'opinion') from the Croatian Psycholinguistic Database (Hrvatska psiholingvistička baza; Peti-Stantić et al. 2018, 2019, 2021). LD is a common test of word recognition. The dependent variable from the LD task was response times (median; $\mathrm{ms}$ ). These variables were recorded for performances on all trials, as well as specifically on concrete word, abstract word, and pseudoword trials.

PEBL Trail Making Test ( $A$ and $B$ ) - Subjects were to click on circles in a given sequence. Test $A$ consisted of two subtests in which the subjects were to click on circles with either numerals from 1 to 22 or letters of the Croatian alphabet $A-Z$ (letters with diacritics were excluded), respectively. In Test B they were to alternate between circles with numerals $(1-12)$ and letters $(A-L)$. Subjects proceeded to the successive parts of the task at their own pace. The ratio between median responses on $B$ and the numeral subtest was used for allocating the subjects into the verbal and nonverbal conditions. One practice trial for each subtask was conducted. There were no dependent variables from the Trail Making Test.

PEBL Corsi Block-tapping Test (CBTT) - Subjects were presented with nine blue blocks which would lit one at a time in a given order. Both the inter-stimulus and inter-trial intervals were $1000 \mathrm{~ms}$. Subjects were to repeat the sequence of lit blocks by clicking on the same blue blocks. The first level contained twoblock trials. After every two trials, subjects advanced to the next level assuming they completed at least one trial of each level. CBTT is considered to be a measure of visuospatial working memory and is associated with both prefrontal and parietal activity (Lancia et al. 2018). We recorded (1) memory span and (2) response times (median; $\mathrm{ms}$ ). Three practice three-block trials were conducted.

PEBL Tower of London (ToL) - Subjects were to individually move colored disks or balls on pegs from an initial state to match a goal state while making as few moves as possible, with progressive difficulty. Twelve trials were analyzed. The test is believed to reflect processes of cognitive planning as good 
performance on the task depends on composing a plan, maintaining it in working memory, and carrying the plan out in the task context (Piper et al. 2012). ToL is also often used as a measure of executive functioning. Furthermore, performance on ToL is associated with activity in the dorsolateral prefrontal and parietal cortices (Lazerom et al. 2000). Dependent variables included (1) accuracy (the raw number of correct trials) and (2) response times (median; ms).

PEBL Wisconsin (Berg) Card Sorting Test (WCST) - Subjects were presented with four piles of cards from a 64-card deck differing in the shapes, number, and color of figures depicted on the cards. On each trial, subjects were given another card which they were supposed to match with one card from the four piles according to a given rule (either shape, number, or color). The rule was not conveyed to the subjects, but they were to infer the rule themselves through a trial and error process. Subjects were informed after every trial whether they performed correctly or incorrectly $(500 \mathrm{~ms})$. The rule changed after ten correct responses. 128 trials were analyzed. WCST is associated with executive functioning and set-shifting (Piper et al. 2012), and prefrontal functioning (Sumitani et al. 2006). Dependent variables included (1) perseverative errors (percentage on all trials), (2) failure to maintain set, (3) and response times (median; $\mathrm{ms}$ ). Perseverative errors include inaccurate responses to a new category (i.e., rule) which would have been correct for the immediately preceding category. A failure to maintain set included situations when the subject made five correct responses in a row but failed to make the 10 correct responses that are required to complete the category.

\subsection{Statistical analyses}

Statistical analyses were conducted in JASP (Version 0.11.1.0) (JASP Team 2020). The independentsample Student t-test with Welch's correction was used for comparisons of non-categorical variables between the verbal and nonverbal groups. Cohen's $d$ is reported for effect sizes. The chi-square test was used to compare categorical variables between groups. We report the Likelihood ratio because of the small sample size, along with Cramer's $V$ for effect sizes. Spearman correlation coefficients were used for investigating associations between stone toolmaking and neuropsychological variables.

\section{Results}

\subsection{Verbal vs. nonverbal comparisons}

There were no significant differences between the groups in age $\left(t_{(10.720)}=1.730, p=.112, d=0.951\right)$, the male-to-female ratio $\left(\mathrm{X}^{2}(1,13)=0.630, \mathrm{p}=.427, \mathrm{~V}=.220\right)$, or the TMT B:A time ratio $\left(\mathrm{t}_{(6.963)}=1.061, \mathrm{p}=\right.$ $.311, d=0.591)$.

\subsubsection{Chopper task}

Results are shown in Table 1. Although visual examination of the descriptive data shows that the verbal group scored better than the nonverbal group on all variables, none of the differences were significant. The highest t-value, as well as the only large effect size, were found for chopper quality. 
Debitage and core analyses for the subjects who unsuccessfully completed the task revealed they failed to produce a single viable flake. One of these subjects fractured three pebbles in half during the task and the task for this subject was subsequently aborted after an ad hoc decision by the researchers. Another subject halved one pebble. This and two other subjects aborted the task after stating they felt unable to produce a flake. All of these subjects were the only subjects rated with 1 by both of the raters on striking platform selection, yet mean values for strike quality in these subjects was 3.50 , suggesting that striking an unfit striking platform contributed most to the subsequent failure to complete the task in these subjects. Examination of the video materials suggested that these subjects struck too far away from the pebble edge, indicating that these subjects failed to acquire the knowledge of adequate platform angle and depth (distance of the striking point from pebble edge) or that they lacked precision. We further compared subjects who completed the chopper task and those who didn't on the stone toolmaking and neuropsychological variables but found no significant differences (all $p>.100$ ). The only large effect size was found for the number of strikes in the chopper task (32.125 \pm 38.498 vs. $64.500 \pm 35.454$, respectively).

Table 1

Comparisons between the verbal and nonverbal groups on the chopper task

\begin{tabular}{|lllllll|}
\hline & Verbal & Nonverbal & $\mathbf{t}$ & $\mathbf{d f}$ & $\mathbf{p}$ & Cohen's d \\
\hline Striking platform selection & 3.964 & 2.750 & 1.254 & 8.756 & .242 & 0.707 \\
& $(1.388)$ & $(1.994)$ & & & & \\
\hline Strike quality & 4.083 & 3.500 & 1.083 & 9.934 & .305 & 0.625 \\
& $(0.970)$ & $(0.894)$ & & & & \\
\hline Flake quality & 3.750 & 2.667 & 1.145 & 8.558 & .283 & 0.646 \\
& $(1.323)$ & $(1.966)$ & & & & \\
\hline Chopper quality & 3.929 & 2.500 & 1.614 & 9.409 & .140 & 0.906 \\
& $(1.367)$ & $(1.761)$ & & & & \\
\hline Number of strikes & 36.333 & 49.500 & 0.563 & 7.899 & .589 & 0.325 \\
\hline Chopper successfully made? & $(49.891)$ & $(28.198)$ & & & & \\
\hline YES 6/7 & YES 3/6 & $X^{2}{ }_{(1,13)}=1.989, p=.158, V=0.386$ \\
\hline
\end{tabular}

\subsubsection{Sidescraper task}

Results are shown in Table 2. Although visual examination of the descriptive data shows that the verbal group scored better than the nonverbal group on all variables, the verbal group scored significantly better 
only in flake quality, with a large effect size. A large effect size was also found for the number of strikes during flaking.

Table 2

Comparisons between the verbal and nonverbal groups on the sidescraper task

\begin{tabular}{|lllllll|}
\hline & Verbal & Nonverbal & $\mathbf{t}$ & $\mathbf{d f}$ & $\mathbf{p}$ & $\begin{array}{c}\text { Cohen's } \\
\mathbf{d}\end{array}$ \\
\hline Striking platform selection & 4.071 & 3.889 & 0.361 & 10.130 & .726 & 0.197 \\
\hline Strike quality & $(1.113)$ & $(0.689)$ & & & & \\
\hline Flake quality & 3.833 & 3.417 & 0.781 & 8.982 & .455 & 0.451 \\
& $(0.753)$ & $(1.068)$ & & & & \\
\hline Working edge selection & 4.214 & 3.222 & 2.669 & 8.504 & .031 & 1.485 \\
\hline Working edge utilization & $(0.533)$ & $(0.800)$ & & & & \\
\hline Retouch quality & 4.595 & 4.556 & 0.181 & 10.996 & .858 & 0.101 \\
\hline Sidescraper quality & $(0.418)$ & $(0.360)$ & & & & \\
\hline Number of strikes & 4.214 & 3.917 & 0.689 & 10.873 & .503 & 0.383 \\
\hline Three sidescrapers successfully & $(0.798)$ & $(0.751)$ & & & & \\
\hline made? & 3.310 & 2.778 & 0.926 & 10.395 & .378 & 0.515 \\
\hline Note: Means are reported. Standard deviations appear in parentheses. & $(0.997)$ & $(1.073)$ & & & & \\
\hline & 3.191 & 2.417 & 1.383 & 10.969 & .190 & 0.770 \\
\hline & $(1.056)$ & $(0.941)$ & & & & \\
\hline & 15.500 & 33.000 & 1.808 & 6.516 & .117 & 1.044 \\
& $(8.689)$ & $(22.054)$ & & & & \\
\hline
\end{tabular}

Four subjects produced only two viable sidescrapers. Two of these subjects also failed to produce the chopper. One subject's failure was attributable to poor flake production, while three subjects displayed very poor retouch.

Neither Student and Wilcoxon signed-rank paired samples t-tests showed any significant differences between performances on the quartz chopper and chert sidescraper tasks in any of the comparable variables, suggesting the two tasks were similarly difficult for the subjects. Thus, we found no evidence 
for a test-retest effect for flaking or other specific production steps and no evidence for performance variation in flaking as a function of raw material type.

Means and standard deviations for flake quality in the chopper and sidescraper tasks in the whole sample were $3.250 \pm 1.674$ and $3.756 \pm 0.821$, respectively, and were $3.269 \pm 1.666$ and $2.833 \pm 1.043$ for tool quality, respectively. Although these differences turned insignificant, it is perhaps notable that the two comparisons display contrasting directions of differences in raw values between the two groups. This possibly suggests that while flaking might have been insignificantly easier to acquire in the sidescraper compared to the chopper task, it would appear that retouch was more poorly acquired compared to flaking in the sidescraper task. Indeed, a paired samples t-test confirmed that subjects performed significantly worse on retouch quality compared to flake quality in the sidescraper task $(z=72.0, p=.011$, $\left.r_{b}=.846\right)$, but not compared to flake quality and chopper quality in the chopper task. Still, explorative analyses revealed that retouch quality was positively associated with chert flaking, namely with the number of strikes $(\rho=-.678, p=.015)$ and flake quality $(\rho=.729, p=.005)$, with the converging data thus indicating that chert flaking and retouch have both shared and distinct underlying processes during early acquisition.

Subjects performed significantly better on striking platform selection $\left(z=77.0, p=.028, r_{b}=.703\right)$ compared to retouch, but not flake quality in the sidescraper task, indicating that specific pre-flaking steps might have been easier to acquire and/or execute compared to retouch, but not flaking in the sidescraper task. Furthermore, subjects scored significantly better on both working edge selection $(z=78.0, p=.003$, $\left.r_{b}>.999\right)$ and working edge utilization $\left(z=91.0, p=.002, r_{b}>.999\right)$ compared to retouch quality, indicating that subjects relatively successfully acquired specific declarative knowledge about retouch, but they had difficulties in execution.

\subsection{Post-experimental interview}

Four subjects ( 3 verbal: 1 nonverbal, 2 males: 2 females) stated that they found it easy to apply force to produce a flake in the chopper task, while six subjects stated the opposite ( $2 \mathrm{~V}$ : 4 NV, 5 M: 1 F). Two subjects stated they found it easy to select the adequate striking platform and flaking angle in the sidescraper task ( $0 \mathrm{~V}: 2 \mathrm{NV}, 2 \mathrm{M}$ : $0 \mathrm{~F}$ ), while seven subjects stated the opposite ( $5 \mathrm{~V}: 2 \mathrm{NV}, 2 \mathrm{M}: 5 \mathrm{~F})$. Three subjects found retouch to be easy ( $1 \mathrm{~V}: 2 \mathrm{NV}, 0 \mathrm{M}: 3 \mathrm{~F})$, and four expressed opposed opinions ( $2 \mathrm{~V}: 2 \mathrm{NV}, 2$ M: 2 F).

Descriptive data show that subjects in the verbal group tended to favor quartz flaking, but disfavor chert flaking. This does not seem related to the stone toolmaking performances in the verbal and nonverbal groups because the descriptive data showed that the verbal group performed better on average than the nonverbal group on all variables on both tasks. Males appeared more induced to produce an F0 compared to A0 response, while females showed an opposite trend. Further, only females had an R1 response on the interview. 
Not unimportantly, two female subjects stated they flaked rather cautiously in both tasks due to fear they would injure their non-dominant (left) hand. One of these subjects failed at both the quartz chopper and chert sidescraper tasks.

\subsection{Stone toolmaking and neuropsychological variables 3.3.1. Chopper task}

There were no significant correlations between any of the chopper and neuropsychological variables.

\subsubsection{Sidescraper task}

Corsi Block-tapping Test (visuospatial working memory) - Because there were numerous significant correlations between the Corsi and sidescraper variables, they are displayed in Table 3.

Table 3

Correlations between the Corsi Block-tapping Test and sidescraper variables

\begin{tabular}{|lll|}
\hline & Memory span & \multicolumn{1}{l|}{ Response times (ms) } \\
\hline Striking platform selection & $\mathrm{ns}$ & $\mathrm{ns}$ \\
\hline Strike quality & $.639(.025)$ & $.673(.017)$ \\
\hline Flake quality & $.627(.022)$ & $\mathrm{ns}$ \\
\hline Working edge selection & $\mathrm{ns}$ & $\mathrm{ns}$ \\
\hline Working edge utilization & $.565(.044)$ & $.608(.027)$ \\
\hline Retouch quality & $.631(.021)$ & $.681(.010)$ \\
\hline Sidescraper quality & $.684(.010)$ & $.759(.003)$ \\
\hline Number of strikes & $-.813(.001)$ & $-.701(.011)$ \\
\hline $\begin{array}{l}\text { Note: } \text { The } \rho \text {-coefficients are reported, while the p-values appear in parentheses. ns = not significant }(\mathrm{p} \\
>.05)\end{array}$ & \\
\hline
\end{tabular}

Tower of London (cognitive planning, executive functioning) - Retouch quality was significantly positively and moderately correlated with the total time $(\rho=.596, p=.032)$.

Wisconsin Card Sorting Test (executive functioning, cognitive flexibility) - Strike quality was significantly negatively and moderately correlated with the failure to maintain set $(\rho=-.595, p=.041)$. Retouch quality was significantly negatively and weakly-to-moderately correlated with the perseverative error rate $(\rho=$ $-.546, p=.053)$ and failure to maintain set $(p=-.547, p=.053)$. Sidescraper quality was significantly positively and moderately correlated with the response times $(\rho=.561, p=.046)$.

Lexical decision (word recognition) - Only response times on the pseudoword trials were significantly positively and either moderately-to-strongly or strongly correlated with flake quality $(\rho=.754, p=.003)$, 
working edge utilization $(\rho=.773, p=.002)$, retouch quality $(\rho=.651, p=.016)$, and sidescraper quality $(\rho$ $=.707, \mathrm{p}=.007)$.

Verbal fluency (lexical production) - Regarding letter fluency, only cluster size was significantly negatively and moderately correlated with sidescraper quality $(\rho=-.593, p=.042)$. Regarding action fluency, productivity was significantly positively and moderately correlated with strike quality $(\rho=.624, p$ $=.030)$, as well as significantly negatively and moderately with the number of attempted strikes $(\rho=$ $-.583, p=.047$ ). Further linguistic analyses of the output on action fluency revealed that strike quality ( $\rho$ $=.758, p=.004)$ was significantly positively and strongly correlated with the rate of syntactically transitive verb production. There were no significant correlations with the rate of semantically transitive verb production.

\section{Discussion}

\subsection{Comparisons between verbal and nonverbal groups and analyses of the stone toolmaking data}

Although the descriptive data showed that subjects in the verbal group performed better on all of the stone toolmaking ratings, the only significant difference $(p<.05)$ was found for flake quality in the chert sidescraper task. Because Welch's test is believed to considerably reduce the likelihood of type I error and because very small samples might lead to type II errors (Delacre et al. 2017; Derrick et al. 2016), it appears more likely that the non-significance of some of the $p$-values from the verbal vs. nonverbal comparisons are the result of type II error than that the significant difference in chert flake quality between the groups is a product of type I error. Furthermore, some effect sizes were moderate and strong on both tasks. Results remained unchanged after analyzing the differences between groups using the non-parametric Mann-Whitney $U$ test. However, because gestures by the demonstrator were allowed in the nonverbal condition in our experiment and because gestures have also been found to facilitate the acquisition of Oldowan-like chert flaking (Cataldo et al. 2018; Morgan et al. 2015), it is possible that both verbal and gestural teaching may have similar effects on the acquisition of Oldowan-like chert flaking (cf. Bohn et al. 2020). Be that as it may, our statistical data from the group comparisons are inconclusive and it remains unclear whether the null hypothesis can be rejected.

Still, descriptiva data show that subjects in the verbal group tended to favor quartz flaking, but disfavor chert flaking, yet this did not seem related to the stone toolmaking performances in the verbal and nonverbal groups because the descriptive data showed that the verbal group performed better on average than the nonverbal group on all variables on both tasks. Thus, although subjects in the verbal group may have scored (not statistically significant) better compared to the nonverbal group on the chert sidescraper task, they still might have perceived the task as more demanding and/or displeasing.

There were no significant within-sample differences between the two tasks in any of the stone toolmaking variables, tentatively indicating that chert flaking for sidescrapers was not easier to acquire 
and execute than quartz flaking for choppers. Additionally, this suggests that there was no test-retest effect, as well as that there were no effects of task and/or raw material type on the stone toolmaking performance. Nevertheless, because of the small sample size, our results are merely explorative and should be taken with caution.

Subsequent explorative analyses revealed that subjects were significantly better on flake quality compared to retouch quality on the chert sidescraper task, indicating that retouch may have been more demanding for the subjects to acquire and/or execute. Nevertheless, flake quality and retouch quality on the chert sidescraper task were significantly positively correlated, tentatively suggesting that performances on chert flaking and retouch have both shared and distinct underlying processes during early acquisition. Additionally, subjects scored significantly better on working edge selection and working edge utilization compared to retouch quality, indicating that subjects relatively successfully acquired specific declarative and procedural knowledge about retouch, but they had difficulties in execution.

\subsection{Post-experimental interview}

In general, subjects showed different preferences for different aspects of the stone toolmaking experiment; namely, for quartz flaking (which they associated mostly with the application of high force), chert flaking (which they associated mostly with selecting the adequate striking platform and flaking angle), and retouch. The mere existence of these preferences indicates that subjects perceived the two stone toolmaking tasks differently. There were only two subjects who expressed they found it easy to flake chert for sidescrapers and seven subjects with an opposite response in the interview, suggesting that the subjects in our sample were more likely to disfavor striking platform selection and flaking in general in the chert sidescraper task than not. This was not the case for the quartz flaking response, where the ratio was four-to-six.

Interestingly, descriptive data suggested disproportionate preferences between male and female subjects across the three post-experimental interview responses (cf. Arthur 2010; Bird 1993; Brandt et al. 2006; de Beaune 2019; Gifford-Gonzalez 1993; Keeley 2010; Sassaman 1993; Tumler et al. 2017; Waguespack 2005). The data suggest again that at least some subjects perceived quartz flaking for choppers and specific aspects of chert retouch very differently and if they preferred one, they were likely to disfavor the other.

\subsection{Correlations between stone toolmaking and neuropsychological variables}

Strikingly, while there were absolutely no significant correlations between the quartz chopper and neuropsychological variables, there was an abundance of significant correlations with the chert sidescraper variables. Importantly, this does not imply that there are differences in the qualities of the quartz chopper and chert sidescraper datasets. Although the correlations with the quartz chopper variables were not significant, the correlation coefficients in many cases showed an opposite direction to that observed in the correlations with the comparable chert sidescraper variables. This suggests that 
there was disproportionate involvement of different cognitive capacities on both tasks, but these effects were smaller and not significant in the quartz chopper task.

Moderate-to-strong and strong significant correlations were found between most of the chert sidescraper and visuospatial working memory variables. Results indicate that subjects with a higher memory span (i.e., able to retain more pieces of information on the location and sequence of lit blocks) and who had slower response times on CBTT were rated better on both chert flaking and retouch. Interestingly, better performance on the chert sidescraper task was associated with slower rather than faster response times. Clearly, however, these slower response times were not associated with poorer performance (i.e., memory span) on the CBTT. While it is difficult to interpret this result, this might suggest that subjects who invested more time into conscious processing of visuospatial information were better on the chert sidescraper task. The strengths of the correlation coefficients were comparable across both the chert sidescraper and the two CBTT variables. The only two chert sidescraper variables which exhibited nonsignificant correlations were striking platform and working edge selection. The former suggests that visuospatial working memory was not associated with the visual assessment of the platforms and knapping faces on the chert core surface before striking. The lack of significant correlations with working edge selection might reflect the facts that there is only a very limited number of possible working edges on a flake and that the subjects were taught to select the longer edges, implying that working edge selection might be more dependent on simple declarative rather than procedural knowledge.

Retouch was weakly-to-moderately and moderately significantly correlated to several executive functioning and cognitive flexibility measures. Subjects who were rated higher on retouch quality were slower in the ToL task, possibly suggesting, similarly to the CBTT results, that subjects who invested more time into conscious planning of the steps needed to complete the ToL task displayed better retouch. Subjects who were rated higher on retouch quality also made fewer perseverative errors and recorded fewer failures to maintain set on WCST, indicating better performance on executive functioning and cognitive flexibility measures. These results suggest that chert flaking and retouch underlie both shared and different cognitive processes during early acquisition in modern humans, with retouch being executively more demanding than flaking.

These results suggest that the increased metabolic activity in parts of the parietal cortex and secondary motor areas during Oldowan-like-flaking-related behaviors might be partly attributed to the demands of visuospatial working memory. Furthermore, the association between retouch and executive functioning possibly explains why previous studies have failed to detect Oldowan-associated increased prefrontal metabolic activity.

Significant correlations were also found for the linguistic tasks. Both chert flaking and retouch were significantly moderately-to-strongly and strongly correlated with the response times on the pseudoword trials of the LD task. Similar to the CBTT and ToL, these correlations were positive, indicating that subjects who were slower in identifying a string of visually presented letters as a pseudoword were better in chert flaking and retouch. Importantly, there were no significant correlations between any of the 
response times variables across the four neuropsychological tasks (CBTT, ToL, WCST, and LD; all p > .199), indicating the four variables reflect different aspects of cognitive processing speed. Because there were no significant correlations between the stone toolmaking variables and the response times on word trials (and neither concrete nor abstract word trials), this result does not necessarily reflect an association between stone toolmaking performance and linguistic processing. Pseudoword recognition on visual LD has been associated with greater demands in visual attention, especially in longer pseudowords. This is because pseudowords are presumably mostly analytically processed in the brain, i.e., only specific orthographic sequences (e.g., syllable-corresponding sequences) are processed at a given point and each sequence of the pseudoword requires a new visual attentional window during which the pronunciation of the sequence can be computed and compared to the phonological lexicon (Valdois et al. 2006; cf. Wong et al. 2020). Because we also included abstract word trials and because abstract words are usually longer than concrete words (Reilly et al. 2012), it is possible that our pseudowords were also long enough to exert greater visual attentional demands. This putative visual attentional role in pseudoword recognition, and chert flaking and retouch should not be confused with the proposed role of visuospatial working memory as inferred from the correlations with CBTT. Attentional processes are different between the two tasks since on CBTT, attention is guided by the task via programmed time intervals, while on visual LD, the speed and quality of the attentional processes depend on the quality and extent of the individual subject's analytical capacity. Also, working memory demands in pseudoword recognition are arguably considerably lower compared to the CBTT, given that there were up to nine levels on the CBTT (nine lit blocks in a given sequence), while words (and thus pseudowords) are typically only a few syllables long, implying there are considerably fewer pieces of information to be retained in the working memory until a subject can decide whether the presented stimulus is a word or not compared to recalling in which locations and sequence were blocks on the screen lit.

Interesting results were obtained from correlations with the verbal fluency variables. Subjects who built smaller consonant-vowel clusters on letter fluency were rated better on chert sidescraper quality. Notably, Uomini \& Meyer (2013) reported in their fTCD study correlations between the lateralization patterns during Acheulean-like chert biface manufacture and silent letter fluency. This might suggest that these correlations with letter fluency are not specific for either chert biface or chert sidescraper manufacture. Nevertheless, there are presumably important differences between silent and overt verbal fluency, while Uomini \& Meyer (2013) further administered switching letter fluency (to ensure continuous word generation and, thus, continuous task-related blood flow; cf. Meyer et al. 2014), in which the letter cue would change after a specific interval (whilst there was a single cue in our study). Also, they investigated these phenomena in expert knappers, while we studied early acquisition. In any case, smaller clusters imply the subjects relied less on successively generating words with similar consonant-vowel structures at the beginning or end of the word (e.g., sharing the first or last syllable). In other words, subjects who were better on the chert sidescraper task had retrieved phonologically more diverse words on letter fluency with respect to the incipient or ending consonant-vowel structures. Healthy subjects typically rely considerably less on clustering on letter fluency compared to semantic fluency (cf. Gabrić \& Vandek 2021b). Also, although the correlation with productivity on letter fluency was weak and not significant ( $\rho$ 
$=.372, \mathrm{p}=.234)$, it had a positive direction, indicating that better chert sidescraper quality was not associated with lesser productivity on letter fluency.

Subjects who generated more verbs and/or verb-object phrases on action fluency had better ratings for strike quality and needed fewer strikes to complete the chert sidescraper task. This is in line with an evergrowing body of research indicating that action language processing relies on brain networks and cognitive processes underlying real action observation and execution (see Introduction). Furthermore, subjects who were rated better in strike quality produced syntactically, but not semantically transitive verbs at higher rates (where the subject stands for an agent and the verb stands for a transitive action). There were in fact no significant correlations with the rate of the production of semantically transitive verbs. Thus, although in the Introduction we argued that striking a core to flake is a semantically transitive event, our results suggest that there were similarities in the cognitive processes underlying striking to flake and the production of syntactically, but not semantically transitive verbs, tentatively suggesting that some level of action schematization was after all needed for a more successful early acquisition of striking a chert core to produce flakes in modern humans.

\subsection{Evolutionary implications}

Because we tested modern humans and not the actual hominin species which engaged in Oldowan knapping behaviors, it is highly questionable whether any evolutionary implications can be drawn from our research. We can only speculate and even that only if we controversially assume that we would have obtained similar results had we tested the early hominins instead of modern humans. Although we do not believe this to be true (or that the PEBL test battery would be suitable for early hominins for that matter), we currently do not see any other possibility to extract evolutionary implications from our data but to express a few controversial speculations based on the aforementioned axiom. It should also be kept in mind that we investigated processes during early acquisition. Thus, our already controversial proposals may not necessarily apply to expert knappers.

The stone toolmaking data possibly suggest that Oldowan hominins perceived quartz and chert knapping, and chert retouch very differently. This suggestion is in line with the results of lithic analyses from sites in Olduvai Gorge showing that in periods when chert was available, it was extensively used, with dramatic changes in the knapping behavioral repertoire and without apparent acclimation periods (Kimura 2002; McHenry \& de la Torre 2018). Arguably, the hominins perceived the greater suitability of chert for flaking and retouch compared to quartz and lava, and changed their knapping behaviors accordingly, as already speculated by de la Torre \& Mora (2018). Furthermore, Oldowan hominins might have shown preferences for one or the other behavior and might have struggled more in acquiring other behaviors or even disliked the other behaviors (cf. Baena et al. 2019). Thus, although individual hominin groups appear to have mastered the different knapping behaviors (when the preferred raw material was available), it is possible that some individuals within those groups would have preferred or disfavored specific knapping behaviors during early acquisition. In turn, this might suggest the presence of considerable intragroup differences in the quality of performance on specific knapping behaviors in these hominins groups, as well as the possibility that some individuals within these groups preferred or 
engaged only in specific knapping behaviors. Furthermore, because in our study chert flaking was associated with cognitive performance, eventual intragroup differences in the quality of chert flaking may reflect intragroup differences in, among others, visuospatial working memory span or other cognitive capacities. Unfortunately, intragroup variations in the level of knapping skill in Oldowan assemblages are alarmingly understudied, while archaeology in general has typically focused on the variations in highskilled knappers as opposed to representative knapper samples or entire assemblages (Bamforth \& Finlay 2008).

Data from the correlations between the stone toolmaking and neuropsychological variables might suggest that while Oldowan hominins did not necessarily need to considerably employ cognitive functions during quartz flaking (at least in the context of chopper manufacture), they might have relied on visuospatial working memory and visual attention during chert flaking and retouch, as well as executive functioning during retouch specifically. The disproportionate associations with visuospatial working memory and attention across the two stone toolmaking tasks might be due to the differences in the visuo-haptic experience of the two raw materials. In our study, for example, quartz pebbles were of very similar morphology (flat and round or oval), while the chert cores displayed a degree of surface irregularity, even though MB, after cortex removal, preliminary flaked the cores to morphologically assimilate them one to another. However, the association of retouch with executive functioning (although not as strong as with visual working memory) remains striking. This result possibly suggests that Oldowan hominins had a certain modern-like level of ability in cognitive planning, as well as cognitive flexibility, i.e., being able to adjust their behavior according to contextual changes during the goal-directed task at hand. Retouch has not been addressed in neuroimaging studies, which is perhaps why the studies failed to find associations between prefrontal metabolic activity and Oldowan-like knapping. This result is also contrary to the suggestion by Putt et al. (2017) that the "cognitive abilities [...] were more ape-like than human-like among hominin toolmakers prior to $1.8 \mathrm{Ma."}$

Following the current line of speculations, the results from the correlations with the action fluency variables might suggest that Oldowan hominins had reached a certain level of modern-like schematized (compared to conceptual) action processing. Further, our results controversially suggest that the Oldowan hominins already exhibited to some degree the cognitive action processing networks underlying action language and specifically syntactically transitive verb-object phrases in modern humans. This is not to say that Oldowan hominins possessed some kind of language with action semantics and verb-object phrases (although it remains a possibility). This is merely to say that some of the prerequisites for these behaviors might have been (partly) in place in Oldowan hominins. At any rate, this provides the first evidence for an association between Palaeolithic stone tool making, and action language and syntactic transitivity, albeit in modern humans. Ending this paragraph with a note, we would caution the readers of this paper against categorizing these verb-object phrases as "simple", "simple language", "simple transitive frames", etc. While it can be in lay's words said that, for example, gledati televiziju 'to watch television' is an example of a "simple" syntactically transitive verb-object phrase because there can be no fewer than two morphological elements (one for the verb and one for the object), the notions of simplicity and complexity of language in discussions on language evolution are typically not (well) defined and 
they are not backed by a linguistic ontology. Also, it should be kept in mind that our interpretations are based on results from Croatian-dialects data where the infinitive form is formed by adding the suffix $-t(i)$ or -ć(i) to the verb stem, while the direct object is in the accusative case, implying an addition of a case-, gender-, and number-appropriate grammatical suffix to the stem. Both grammatical processes may lead to phonological alternations (Barić et al. 2005). Thus, these verb-object phrases may not be as simple as one might think.

Because Oldowan hominins appear to have been relatively cognitively, anatomically, culturally, and/or differently ready for the inclusion of chert for stone toolmaking, our results suggest that the Oldowan hominin populations had achieved certain modern-like levels of visuospatial working memory and executive functioning before the periods of chert availability. Thus, our results also suggest that the levels of these capacities were not phylogenetically associated with chert knapping and, due to the relative stability and simplicity of the repertoire of knapping behaviors throughout Oldowan (cf. Bower 1977; Proffitt 2018), it is questionable whether it can be hypothesized that these capacities were somehow evolutionarily fine-tuned via chert knapping. Come what may, the fact that quartz flaking in the context of chopper manufacture was not associated with cognitive performance suggests that quartz chopper manufacture does not reflect the full extent of cognitive capacities of Oldowan populations. Furthermore, because research has, among others, shown that there was a considerable increase in hominin brain size from the time of australopithecines to Homo erectus which may have been associated with novel cognitive adaptations (Toth \& Schick 2018), but that both quartz and chert tool manufacture exhibited relative technological constancy throughout Oldowan, it is possible that neither quartz nor chert flaking (and retouch) reflect the full cognitive extent of Oldowan populations (cf. Toth 1985).

Importantly, knapping behaviors do not necessarily constitute the entire tool behavior repertoire of Oldowan populations. Stone tool technology encompassed other behaviors such as lithic raw material procurement, selection, transport, and curation, all of which were interdependent with resource distribution and quality (Goldman-Neuman \& Hovers 2009, 2012; Harmand 2009). Furthermore, use-wear analyses of artifacts from Kanjera South, dated to $\sim 2.0 \mathrm{Ma}$, have hinted at the possibility of wooden tool manufacture on that site (Lemorini et al. 2014; cf. Bello-Alonso et al. 2019), while wooden tool use has been observed in wild common chimpanzees (Bandini \& Harrison 2020; Luncz et al. 2012; Pruetz \& Bertolani 2007), yet very limitedly in wild bonobos (Schamberg et al. 2017; cf. Furuichi et al. 2015). Bone tools encompassing flaked bones, bone hammers, and wedges are also reported from Bed II sites at Olduvai, although some of them are associated with the Acheulean as well (Backwell \& d'Errico 2004). Thus, other tool behaviors or other behaviors in general might better reflect the levels of cognitive capacities of Oldowan hominin populations.

Future research should try to replicate these results with larger samples. Our results will hopefully also induce future research on the effects of different raw materials and the associations with different cognitive capacities and linguistic phenomena (cf. Toya \& Hashimoto 2018). However, because we have interpreted our results as suggesting that neither quartz nor chert flaking and retouch may be indicative of 
cognition in Oldowan populations, other avenues of research should also be inspected (cf. Karakostis et al. 2021; Karakostis \& Harvati 2021; Key et al. 2018a,b, 2020; Key \& Dunmore 2018).

\section{Limitations}

Firstly, it is epistemologically problematic to test modern humans to assess cognition in extinct hominin species. Secondly, our sample size was very small, which might have especially been an issue in group comparisons. Thirdly, correlations between the stone toolmaking and neuropsychological variables were calculated for the entire sample, i.e., including subjects in both the verbal and gestural conditions. It is also worth noting that the archaeological identification of retouched tools is epistemologically problematic because retouch on unifacial tools can be the result of purposeful design employed in retouched tool manufacture or a haphazard form emanating from continuous flake edge wear and repair (Rolland \& Dibble 1990).

\section{Declarations}

\section{Acknowledgments}

We thank Joško Barbarić for filming the experiments for data collection. We also thank Lia Vidas, Paul Markotić, and Filip Vukoja for their generous help in raw material procurement and transport. The content of the manuscript has previously appeared online as a preprint (Gabrić et al., 2021b).

\section{Funding}

Partial support for safety equipment and transportation to the sites for the raw material procurement was granted by the Department of Archaeology, University of Zagreb, Croatia. Open Access funding enabled and organized by Projekt DEAL.

\section{Author contributions}

Petar Gabrić: Conceptualization, Material collection Formal analysis, Methodology, Writing - original draft, Writing - review \& editing, Supervision. Marko Banda: Material collection, Material preparation, Formal analysis, Methodology, Writing - review \& editing. Ivor Karavanić: Material collection, Formal analysis, Methodology, Writing - review \& editing, Supervision.

\section{Conflicts of interest/Competing interests}

The authors have nothing to declare.

\section{Ethics approval}

Ethical approval for the study was obtained by the "Etičko povjerenstvo za znanstveno-istraživački rad" of the Faculty of Humanities and Social Sciences, University of Zagreb (dated 2018/10/03). 


\section{Consent to participate}

All participants gave informed consent to partake in the study.

\section{Consent for publication}

All participants gave written consent to the inclusion of material pertaining to themselves, they have acknowledged that they cannot be identified via the paper, and we have fully anonymized them.

\section{References}

1. Adamaszek, M., D’Agata, F., Ferrucci, R., Habas, C., Keulen, S., Kirkby, K. C., Leggio, M., et al. (2016). Consensus paper: Cerebellum and emotion. The Cerebellum, 16(2), 552-576. doi:10.1007/s12311016-0815-8

2. Adornetti, I. (2014). Making tools and planning discourse: The role of executive functions in the origin of language. Humana.Mente: Journal of Philosophical Studies, 27, $221-$ $241 \mathrm{http}: / /$ www.humanamente.eu/index.php/HM/article/view/105

3. Adornetti, I., Chiera, A., \& Ferretti, F. (2018). Embodied cognition e origine del linguaggio: II ruolo cruciale del gesto. Lebenswelt: Aesthetics and Philosophy of Experience, 13, 43-56. doi:10.13130/2240-9599/11107

4. Akazawa, T., Ogihara, N., Tanabe, H. C., \& Terashima, H. (Eds.). (2014). Dynamics of Learning in Neanderthals and Modern Humans Volume 2: Cognitive and Physical Perspectives. Tokyo: Springer. doi:10.1007/978-4-431-54553-8

5. Ambrose, S. H. (2010). Coevolution of composite-tool technology, constructive memory, and language. Current Anthropology, 51(S1), S135-S147. doi:10.1086/650296

6. Amunts, J., Camilleri, J. A., Eickhoff, S. B., Heim, S., \& Weis, S. (2020). Executive functions predict verbal fluency scores in healthy participants. Scientific Reports, 10, 11141. doi:10.1038/s41598-020$65525-9$

7. Andres, M., Pelgrims, B., Olivier, E., \& Vannuscorps, G. (2017). The left supramarginal gyrus contributes to finger positioning for object use: a neuronavigated transcranial magnetic stimulation study. European Journal of Neuroscience, 46(12), 2835-2843. doi:10.1111/ejn.13763.

8. Arbib, M. A. (2005). From monkey-like action recognition to human language: an evolutionary framework for neurolinguistics. Behavioral and Brain Science, 28, 105-167. doi:10.1017/s0140525x05000038

9. Arbib, M. A. (Ed.). (2006). From Action to Language via the Mirror Neuron System. New York: Cambridge University Press. doi:10.1017/CB09780511541599

10. Arbib, M. A. (2011). From mirror neurons to complex imitation in the evolution of language and tool use. Annual Review of Anthropology, 40, 257-273. doi:10.1146/annurev-anthro-081309-145722 
11. Arbib, M. A. (2012). How the Brain Got Language. The Mirror System Hypothesis. New York: Oxford University Press. doi:10.1093/acprof:osobl/9780199896684.001.0001

12. Arbib, M. A. (2015). From action to typology? A neuro-evolutionary perspective. Language and Linguistics Compass, 9(2), 102-117. doi:10.1111/Inc3.12104

13. Arbib, M. A. (2016a). Towards a Computational Comparative Neuroprimatology: framing the language-ready brain. Physics of Life Review, 16, 1-54. doi:10.1016/j.plrev.2015.09.003

14. Arbib, M. A. (2016b). Primates, computation, and the path to language: reply to comments on "Towards a Computational Comparative Neuroprimatology: framing the language- ready brain". Physics of Life Review, 16, 105-122. doi:10.1016/j.plrev.2016.02.003

15. Arbib, M. A. (2017). Dorsal and ventral streams in the evolution of the language-ready brain: linking language to the world. Journal of Neurolinguistics, 43(Part B), 228-253. doi:10.1016/j.jneuroling.2016.12.003

16. Arbib, M. A., Gasser, B., \& Barrès, V. (2014). Language is handy but is it embodied? Neuropsychologia, 55, 57-70. doi:10.1016/j.neuropsychologia.2013.11.004

17. Ardila, A., Bernal, B., \& Rosselli, M. (2016). Why Broca's area damage does not result in classical Broca's aphasia? Frontiers in Human Neuroscience, 10, 249. doi:10.3389/fnhum.2016.00249

18. Arthur, K. W. (2010). Feminine knowledge and skill reconsidered: women and flaked stone tools. American Anthropology, 112, 228-243. doi:10.1111/j.1548-1433.2010.01222.x

19. Aziz-Zadeh, I., Wilson, S. M., Rizzolatti, G., \& lacoboni, M. (2006). Congruent embodied representations for visually represented actions and linguistic phrases describing actions. Current Biology, 16(18), 1818-1823. doi:10.1016/j.cub.2006.07.060

20. Backwell, L. R., \& d'Errico, F. (2004). The first use of bone tools: a reappraisal of the evidence from Olduvai Gorge, Tanzania. Palaeontologia africana, 40, 95-158http://hdl.handle.net/10539/13318

21. Baena, J., Ortiz, I., \& Torres, C. (2019). Good and bad knappers among Neanderthals. In Y. Nishiaki \& O. Jöris (eds.), Learning Among Neanderthals and Palaeolithic Modern Humans: Archaeological Evidence (pp. 95-117). Singapore: Springer. doi:10.1007/978-981-13-8980-1_7

22. Bamforth, D. B., \& Finlay, N. (2008). Introduction: archaeological approaches to lithic production skill and craft learning. Journal of Archaeological Method and Theory, 15, 1-27. doi:10.1007/s10816007-9043-3

23. Banda, M., \& Karavanić, I. (2019). The Mousterian industry of Veternica Cave. Prilozi Instituta za arheologiju u Zagrebu, 36, 5-40. doi:10.33254/piaz.36.1

24. Bandini, E., \& Harrison, R. A. (2020). Innovation in chimpanzees. Biological Reviews, 95(5), 11671197. doi:10.1111/brv.12604

25. Bar-Yosef, O. (2017). Can archaeology tell us about the evolution of cognition and language? Journal of Neurolinguistics, 43, 222-227. doi:10.1016/j.jneuroling.2016.11.009

26. Barham, L., \& Everett, D. (2020). Semiotics and the origin of language in the Lower Palaeolithic. Journal of Archaeological Method and Theory. doi:10.1007/s10816-020-09480-9 
27. Barić, E., Lončarić, M., Malić, D., Pavešić, S., Peti, M., Zečević, V., \& Znika, M. (2005). Hrvatska gramatika. Zagreb: Školska knjiga

28. Baronchelli, A., Chater, N., Pastor-Satorras, R., \& Christiansen, M. H. (2012). The biological origin of linguistic diversity. PLoS One, 7(10), e48029. doi:10.1371/journal.pone.0048029

29. Barsalou, L. W. (2008). Grounded cognition. Annual Review of Psychology, 59, 617-645. doi:10.1146/annurev.psych.59.103006.093639

30. Bednarik, R. G. (2013). Pleistocene palaeoart of Africa. Arts, 2, 6-34. doi:10.3390/arts2010006

31. Bell, J. A. (1994). Interpretation and testability in theories about prehistoric thinking. In C. Renfrew \& E. B. W. Zubrow (eds.), The Ancient Mind: Elements of Cognitive Archaeology (pp. 15-21). Cambridge: Cambridge University Press. doi:10.1017/СВ09780511598388.003

32. Bello-Alonso, P., Rios-Garaizar, J., Panera, J., Pérez-González, A., Rubio-Jara, S., Rojas-Mendoza, R., et al. (2019). A use-wear interpretation of the most common raw materials from the Olduvai Gorge: Naibor Soit quartzite. Quaternary International, 526, 169-192. doi:10.1016/j.quaint.2019.09.025

33. Berwick, R. C., Hauser, M. D., \& Tattersall, I. (2013). Neanderthal language? Just-so stories take center stage. Frontiers in Psychology, 4, 671. doi:10.3389/fpsyg.2013.00671

34. Berwick, R. C., \& Chomsky, N. (2016). Why Only Us: Language and Evolution. Cambridge [etc.]: MIT Press. doi:10.7551/mitpress/9780262034241.001.0001

35. Bickerton, D. (1990). Language and Species. Chicago/London: University of Chicago Press. doi:10.7208/chicago/9780226220949.001.0001

36. Bickerton, D. (2007). Language evolution: a brief guide for linguists. Lingua, 117, 510-526. doi:10.1016/j.lingua.2005.02.006

37. Bird, C. F. M. (1993). Woman the toolmaker: evidence for women's use and manufacture of flaked stone tools in Australia and New Guinea. In H. du Cros \& L. Smith (eds.), Women in Archaeology (pp. 22-30). Canberra: Department of Prehistory, Research School of the Pacific and Asian Studies, Australian National University

38. Boeckx, C. A., \& Fujita, K. (2014). Syntax, action, comparative cognitive science, and Darwinian thinking. Frontiers in Psychology, 5, 627. doi:10.3389/fpsyg.2014.00627

39. Bohn, M., Kordt, C., Braun, M., Call, J., \& Tomasello, M. (2020). Learning novel skills from iconic gestures: a developmental and evolutionary perspective. Psychological Science, 31(7), 873-880. doi:10.1177/0956797620921519

40. Botha, R. (2009). Theoretical underpinnings of inferences about language evolution: the syntax used at Blombos Cave. In Botha, R., \& Knight, C. (Eds.), The Cradle of Language (93-111). New York: Oxford University Presshttp://hdl.handle.net/10019.1/44890

41. Botha, R. (2010). On the soundness of inferring modern language from symbolic behaviour. Cambridge Archaeological Journal, 20(3), 345-356. doi:10.1017/S0959774310000454

42. Botha, R. (2012). Inferring modern language from ancient objects. In K. R. Gibson \& M. Tallerman (eds.), The Oxford Handbook of Language Evolution (pp. 303-312). New York: Oxford University 
Press. doi:10.1093/oxfordhb/9780199541119.013.0030

43. Botha, R. (2015). Teaching and learning subsistence skills: did premodern hominins use language to do it? Cambridge Archaeological Journal, 25(4), 901-908. doi:10.1017/S0959774315000335

44. Botha, R. (2020). Neanderthal Language: Demystifying the Linguistic Powers of Our Extinct Cousins. Cambridge: Cambridge University Press. doi:10.1017/9781108868167

45. Bourguignon, N. J., Braem, S., Hartstra, E., De Houwer, J., \& Brass, M. (2018). Encoding of novel verbal instructions for prospective action in the lateral prefrontal cortex: evidence from univariate and multivariate functional magnetic resonance imaging analysis. Journal of Cognitive Neuroscience, 30(8), 1170-1184. doi:10.1162/jocn_a_01270

46. Bower, J. R. F. (1977). Attributes of Oldowan and Lower Acheulean tools: 'tradition' and design in the early Lower Paleolithic. South African Archaeological Bulletin, 32, 113-126. doi:10.2307/3888658

47. Brandt, S., Weedman, K., \& Shipley, J. (2006). Woman the Toolmaker: Hideworking and Stone Tool Use in Konso, Ethiopia. Abingdon-on-Thames: Routledge

48. Brauer, J., Anwander, A., Perani, D., \& Friederici, A. D. (2013). Dorsal and ventral pathways in language development. Brain and Language, 127, 289-295. doi:10.1016/j.bandl.2013.03.001

49. Braun, D. R., Tactikos, J. C., Ferraro, J. V., \& Harris, J. W. K. (2005). Flake recovery rates and inferences of Oldowan hominin behavior: a response to Kimura 1999, 2002. Journal of Human Evolution, 48, 525-531. doi:10.1016/j.jhevol.2005.02.002

50. Breyl, M. (2020). Triangulating Neanderthal cognition: a tale of not seeing the forest for the trees. WIREs Cognitive Science, 12(2), e1545. doi:10.1002/wcs.1545

51. Brozzoli, C., Roy, A. C., Lidborg, L. H., \& Lövdén, M. (2019). Language as a tool: motor proficiency using a tool predicts individual linguistic abilities. Frontiers in Psychology, 10, 1639. doi:10.3389/fpsyg.2019.01639

52. Bruner, E. (2010). Morphological differences in the parietal lobes within the human genus. Current Anthropology, 51, S77-88. doi:10.1086/650729

53. Bruner, E., Fedato, A., Silva-Gago, M., Alonso-Alcalde, R., Terradillos-Bernal, M., Fernandez-Durantes, M. A., \& Martín-Guerra, E. (2018). Cognitive archeology, body cognition, and hand-tool interaction. Progress in Brain Research, 238, 325-345. doi:10.1016/bs.pbr.2018.06.013

54. Bruner, E., Spinapolice, E., Burke, A., \& Overmann, K. A. (2018). Visuospatial integration: paleoanthropological and archaeological perspectives. In L. Di Paolo, F. Di Vincenzo, F. De Petrillo (eds), Evolution of Primate Social Cognition: Interdisciplinary Evolution Research (pp. 299-326). Cham: Springer. doi:10.1007/978-3-319-93776-2_19

55. Bzdok, D., Hartwigsen, G., Reid, A., Laird, A. R., Fox, P. T., \& Eickhoff, S. B. (2016). Left inferior parietal lobe engagement in social cognition and language. Neuroscience \& Biobehavioral Reviews, 68, 319334. doi:10.1016/j.neubiorev.2016.02.024

56. Casado, P., Martín-Loeches, M., Muñoz, F., Hernández-Gutiérrez, D., Jiménez-Ortega, L., SánchezGarcía, J., et al. (2020). On the interplay between motor sequencing and linguistic syntax: 
electrophysiological evidence. Journal of Neurolinguistics, 53, 100874.

doi:10.1016/j.jneuroling.2019.100874

57. Casielles, E., \& Progovac, L. (2012). Protosyntax: a thetic (unaccusative) stage? Theoria et Historia Scientiarum, 9, 29-48. doi:10.12775/v10235-011-0003-4

58. Cataldo, D. M., Migliano, A. B., \& Vinicius, L. (2018). Speech, stone tool-making and the evolution of language. PLoS One, 13(1), e0191071. doi:10.1371/journal.pone.0191071

59. Chase, P. G., \& Dibble, H. L. (1987). Middle Paleolithic symbolism: a review of current evidence and interpretations. Journal of Anthropological Archaeology, 6, 263-296. doi:10.1016/02784165(87)90003-1

60. Chen, L., Wu, J., Hartwigsen, G., Li, Z., Wang, P., \& Feng, L. (2021). The role of a critical left frontotemporal network with its right-hemispheric homologue in syntactic learning based on word category information. Journal of Neurolinguistics, 58, 100977. doi:10.1016/j.jneuroling.2020.100977

61. Chomsky, N. (2002). On Nature and Language. Cambridge: Cambridge University Press. doi:10.1017/СВ09780511613876

62. Chomsky, N., Gallego, Á. J., \& Ott, D. (2019). Generative grammar and the Faculty of Language: insights, questions, and challenges. Catalan Journal of Linguistics, 2019, 229-261. doi:10.5565/rev/catjl.288

63. Christensen, K. R. (2010). Syntactic reconstruction and reanalysis, semantic dead ends, and prefrontal cortex. Brain and Cognition, 73, 41-50. doi:10.1016/j.bandc.2010.02.001

64. Cohn, N., \& Paczynski, M. (2013). Prediction, events, and the advantage of Agents: the processing of semantic roles in visual narrative. Cognitive Psychology, 67, 73-97.

doi:10.1016/j.cogpsych.2013.07.002

65. Cohn, N., Parczynski, M., \& Kutas, M. (2017). Not so secret agents: event-related potentials to semantic roles in visual event comprehension. Brain and Cognition, 119, 1-9.

doi:10.1016/j.bandc.2017.09.001

66. Collier, K., Bickel, B., van Schaik, C. P., Manser, M. B., \& Townsend, S. W. (2014). Language evolution: syntax before phonology?. Proceedings of the Royal Society B: Biological Sciences, 281, 20140263. doi:10.1098/rspb.2014.0263

67. Conrad, N. J., Malina, M., \& Münzel, S. C. (2009). New flutes document the earliest musical tradition in southwestern Germany. Nature, 460, 737-740. doi:10.1038/nature08169

68. Coolidge, F. L., \& Wynn, T. (2001). Executive functions of the frontal lobes and the evolutionary ascendancy of Homo sapiens. Cambridge Archaeological Journal, 11(2), 255-260.

doi:10.1017/S0959774301000142

69. Coolidge, F. L., \& Wynn, T. (2005). Working memory, its executive functions, and the emergence of modern thinking. Cambridge Archaeological Journal, 15(1), 5-26. doi:10.1017/S0959774305000016

70. Coolidge, F. L., \& Wynn, T. (2015). Cognitive archaeology and the cognitive sciences. In E. Bruner (Ed.), Human Paleoneurology (pp. 177-208). Cham: Springer. doi:10.1007/978-3-319-08500-5_8 
71. Coolidge, F. L., \& Wynn, T. (2016). An introduction to cognitive archaeology. Current Directions in Psychological Science, 25(6), 386-392. doi:10.1177/0963721416657085

72. Corbey, R., Jagich, A., Vaesen, K., \& Collard, M. (2016). The Acheulean handaxe: more like a bird's song than a Beatles' tune? Evolutionary Anthropology, 25, 6-19. doi:10.1002/evan.21467

73. Creissels, D. (2016). Transitivity, valency and voice. Paper presented the European Summer School in Linguistic Typology, Porquerolles. http://www.deniscreissels.fr/public/Creissels-ESSLT.pdf

74. Criado-Boado, F., Alonso-Pablos, D., Blanco, M. J., Porto, Y., Rodríguez-Paz, A., Cabrejas, E., et al. (2019). Coevolution of visual behaviour, the material world and social complexity, depicted by the eye-tracking of archaeological objects in humans. Scientific Reports, 9, 3985. doi:10.1038/s41598019-39661-w

75. d'Errico, F. (2003). The invisible frontier: a multiple species model for the origin of behavioral modernity. Evolutionary Anthropology, 12, 188-202. doi:10.1002/evan.10113

76. d'Errico, F., Villa, P., Pinto Llona, A. C., \& Idarraga, R. R. (1998). A Middle Palaelithic origin of music? Using cave-bear bone accumulations to assess the Divje Babe I bone 'flute'. Antiquity, 72, 65-79. doi:10.1017/S0003598X00086282

77. d'Errico, F., Lawson, G., Vanhaeren, M., \& van Niekerk, K. (2005). Nassarius kraussianus shell beads from Blombos Cave: evidence for symbolic behaviour in the Middle Stone Age. Journal of Human Evolution, 48(1), 3-24. doi:10.1016/j.jhevol.2004.09.002

78. Dannemann, M., He, Z., Heide, C., Vernot, B., Sidow, L., Kanton, S., et al. (2020). Human stem cell resources are an inroad to Neandertal DNA functions. Stem Cell Reports, 15(1), P214-P225. doi:10.1016/j.stemcr.2020.05.018

79. Davidson, I. (2013). Origins of pictures: an argument for transformation of signs. In K. SachsHombach \& J. R. J. Schirra (eds.), Origins of Pictures: Anthropological Discourses in Image Science (pp. 16-46). Cologne: Herbert von Halem Verlag. https://hdl.handle.net/1959.11/14269

80. Davidson, I. (2014). Cognitive evolution and origins of language and speech. In C. Smith (Ed.) Encyclopedia of Global Archaeology (pp. 1530-1543). New York: Springer. doi:10.1007/978-1-44190465-2_668

81. Davidson, I., \& McGrew, W. C. (2005). Stone tools and the uniqueness of human culture. Journal of the Royal Anthropological Institute, 11(4), 793-817. doi:10.1111/j.1467-9655.2005.00262.x

82. de Beaune, S. A. (2019). A critical analysis of the evidence for sexual division of tasks in the European Upper Paleolithic. In K. A. Overmann \& Coolidge F. L. (eds.). Squeezing Minds From Stones: Cognitive Archaeology and the Evolution of the Human Mind (pp. 376-405). Oxford: Oxford University Press. doi:10.1093/oso/9780190854614.003.0019

83. De Beni, R., Pazzaglia, F., Gyselinck, V., \& Meneghetti, C. (2005). Visuospatial working memory and mental representation of spatial descriptions. European Journal of Cognitive Psychology, 17(1), 7795. doi:10.1080/09541440340000529

84. de Heinzelin, J., Clark, J. D., White, T., Hart, W., Renne, P., Wolde Gabriel, G. ... Vrba, E. (1999). Environment and behavior of 2.5-million-year-old Bouri hominids. Science, 284, 625-629. 
doi:10.1126/science.284.5414.625

85. de la Torre, I., \& Mora, R. (2014). The transition to the Acheulean in East Africa: an assessment of paradigms and evidence from Olduvai Gorge (Tanzania). Journal of Archaeological Method and Theory, 21, 781-823. doi:10.1007/s10816-013-9176-5

86. de la Torre, I., \& Mora, R. (2018). Oldowan technological behaviour at HWK EE (Olduvai Gorge, Tanzania). Journal of Human Evolution, 120, 236-273. doi:10.1016/j.jhevol.2018.04.001

87. de la Torre, I., Albert, R. M., Arroyo, A., Macphail, R., McHenry, L. J., Mora, R., et al. (2018). New excavations at the HWK EE site: archaeology, paleoenvironment and site formation processes during late Oldowan times at Olduvai Gorge, Tanzania. Journal of Human Evolution, 120, 140-202. doi:10.1016/j.jhevol.2017.07.018

88. de Lombera-Hermida, A., Rodríguez-Álvarez, X. P., Mosquera, M., Ollé, A., García-Medrano, P., Pedergnana, A., et al. (2020). The dawn of the Middle Paleolithic in Atapuerca: the lithic assemblage of TD10.1 from Gran Dolina. Journal of Human Evolution, 145, 102812.

doi:10.1016/j.jhevol.2020.102812

89. de Lumley, H., Barsky, D., \& Cauche, D. (2009). Archaic stone industries from East Africa and southern Europe: Pre-Oldowan and Oldowan. In K. Schick \& N. Toth (eds.), The Cutting Edge: New Advances into the Archaeology of Human Origins (pp. 55-91). Gosport: Stone Age Institute Press

90. Dediu, D., \& Levinson, S. C. (2013). On the antiquity of language: the reinterpretation of Neandertal linguistic capacities and its consequences. Frontiers in Psychology, 4, 397. doi:10.3389/fpsyg.2013.00397

91. Dediu, D., \& Levinson, S. C. (2018). Neanderthal language revisited: not only us. Current Opinion in Behavioral Science, 21, 49-55. doi:10.1016/j.cobeha.2018.01.001

92. Delacre, M., Lakens, D., \& Leys, C. (2017). Why psychologists should by default use Welch's t-test instead of Student's t-test. International Review of Social Psychology, 30(1), 92-101. doi:10.5334/irsp.82

93. Derevianko, A. P., Shunkov, M. V., Bulatović, L., Pavlenok, K. K., Ulyanov, V. A., Kozlikin, M. B., \& Kandyba, A. V. (2017). New findings on the Middle Paleolithic of the Eastern Adriatic: the earliest settlement at Bioče, Montenegro. Archaeology, Ethnology \& Anthropology of Eurasia, 45(1), 3-14. doi:10.17746/1563-0110.2017.45.1.003-014

94. Derrick, B., Toher, D., \& White, P. (2016). Why Welch's test is Type I error robust. Quantitative Methods for Psychology, 12(1), 30-38. doi:10.20982/tqmp.12.1.p030

95. Desai, R. H., Conant, L. L., Binder, J. R., Park, H., \& Seidenberg, M. S. (2010). Activation of sensorymotor areas in sentence comprehension. Cerebral Cortex, 20(2), 468-478. doi:10.1093/cercor/bhp115

96. Deschamps, I., Baum, S. R., \& Gracco, V. L. (2014). On the role of the supramarginal gyrus in phonological processing and verbal working memory: evidence from rTMS studies.

Neuropsychologia, 53, 39-46. doi:10.1016/j.neuropsychologia.2013.10.015 
97. Domínguez-Rodrigo, M., \& Alcalá, L. (2016). 3.3-million-year-old stone tools and butchery traces? More evidence needed. PaleoAnthropology, 2016, 46-53. doi:10.4207/PA.2016.ART99

98. Dreyer, F. R., \& Pulvermüller, F. (2018). Abstract semantics in the motor system? - An event-related fMRI study on passive reading of semantic word categories carrying abstract emotional and mental meaning. Cortex, 100, 52-70. doi:10.1016/j.cortex.2017.10.021

99. Dreyer, F. R., Picht, T., Frey, D., Vajkoczy, P., \& Pulvermüller, F. (2020). The functional relevance of dorsal motor systems for processing tool nouns: evidence from patients with focal lesions. Neuropsychologia, 141, 107384. doi:10.1016/j.neuropsychologia.2020.107384

100. ELAN (Version 5.8) [Computer software]. (2019) Nijmegen: Max Planck Institute for Psycholinguistics, The Language Archive. Retrieved from https://archive.mpi.nl/tla/elan

101. Everett, D. L. (2016). How Language Began: The Story of Humanity's Greatest Invention. New York/London: Liveright Publishing Corporation

102. Fadiga, L., Craighero, L., \& D'Ausilio, A. (2009). Broca's area in language, action, and music. Annals of the New York Academy of Sciences, 1169, 448-458. doi:10.1111/j.1749-6632.2009.04582.x

103. Fagg, A., \& Arbib, M. A. (1998). Modeling parietal-premotor interaction in primate control of grasping. Neural Networks, 11, 1277-1303. doi:10.1016/S0893-6080(98)00047-1

104. Fazio, P., Cantagallo, A., Craighero, L., D’Ausilio, A., Roy, A. C., Pozzo, T., et al. (2009). Encoding of human action in Broca's area. Brain, 132, 1980-1988. doi:10.1093/brain/awp118

105. Fiebach, C. J., \& Schubotz, R. I. (2006). Dynamic anticipatory processing of hierarchical sequential events: a common role for Broca's area and ventral premotor cortex across domains? Cortex, 42, 499-502. doi:10.1016/s0010-9452(08)70386-1

106. Fotiadou, G., \& Vassiliadou, H. (2017). Transitivity and valency: from theory to acquisition. An overview. Lingvisticæ Investigationes, 40(1), 1-24. doi:10.1075/li.40.1.01geo

107. Foundas, A. L., Leonard, C. M., Gilmore, R. L., Fennell, E. B., \& Heilman, K. M. (1996). Pars triangularis asymmetry and language dominance. Proceedings of the National Academy of Sciences of the United States of America, 93, 719-722. doi:10.1073/pnas.93.2.719

108. Frak, V., \& Cohen, H. (2021). Converging perspectives on the relationship between language and action. Brain and Cognition, 150, 105707. doi:10.1016/j.bandc.2021.105707

109. Frayer, D. W., Radovčić, J., \& Radovičić, D. (2020). Krapina and the case for Neandertal symbolic behavior. Current Anthropology, 61(6), 713-731. doi:10.1086/712088

110. Furuichi, T., Sanz, C., Koops, K., Sakamaki, T., Ryu, H., Tokuyama, N., \& Morgan, D. (2015). Why do wild bonobos not use tools like chimpanzees do? Behaviour, 152, 425-460. doi:10.1163/1568539X00003226

111. Gabrić, P. (2021a). Overlooked evidence for semantic compositionality and signal reduction in wild chimpanzees (Pan troglodytes). Animal Cognition. Online ahead of print. https://doi.org/10.1007/s10071-021-01584-3 
112. Gabrić, P. (2021b). Differentiation between agents and patients in the putative two-word stage of language evolution. Frontiers in Psychology, 12, 684022.

https://doi.org/10.3389/fpsyg.2021.684022

113. Gabrić, P. (2021c). Evolution of Syntax and Semantics from Psycholinguistic and Neurolinguistic Perspectives. M.A. thesis [English translation]: University of Zagreb, Zagreb, Croatia. doi:10.31234/osf.io/e9w4u

114. Gabrić, P. (2021d). Book review: Neanderthal Language: Demystifying the Linguistic Powers of Our Extinct Cousins. Frontiers in Psychology, 12, 702361. doi:10.3389/fpsyg.2021.702361

115. Gabrić, P. (2021e). Evolucija sintakse i semantike iz psiholingvističke i neurolingvističke perspektive. M.A. thesis: University of Zagreb, Zagreb, Croatia. https://doi.org/10.31237/osf.io/3ap9u

116. Gabrić, P. (2022). Corrigendum: Differentiation between agents and patients in the putative two-word stage of language evolution. Frontiers in Psychology, 13, 837686. https://doi.org/10.3389/fpsyg.2021.837686

117. Gabrić, P., Banda, M., \& Karavanić, I. (2018). Palaeolithic toolmaking and the evolution of cognition and language. In T. Strle \& O. Markič (eds.), Proceedings of the 21st International Multiconference Information Society - IS 2018, Volume B: Cognitive Science (pp. 12-16). Ljubljana: Institut "Jožef Stefan". doi:10.5281/zenodo.4674332

118. Gabrić, P., Banda, M., \& Karavanić, I. (2021a). Palaeolithic toolmaking and the evolution of cognition and language [Preprint]. PsyArXiv. https://doi.org/10.31234/osf.io/ahp9u

119. Gabrić, P., Banda, M., \& Karavanić, I. (2021b). Cognitive performance and specific aspects of language processing are associated with Oldowan-like chert flaking and retouch [Preprint]. PsyArXiv. https://doi.org/10.31234/osf.io/p9vyj

120. Gabrić, P., \& Vandek, M. (2021a). Semantic fluency reveals reduced functional connectivity between subcategorical co-hyponyms in recent-onset inpatients with first-episode psychosis. Clinical Linguistics \& Phonetics. Online ahead of print. https://doi.org/10.1080/02699206.2021.1961019

121. Gabrić, P., \& Vandek, M. (2021b). Striking differences in performance patterns across different semantic and phonemic fluency tasks: preliminary data [Preprint]. PsyArXiv. doi:10.31234/osf.io/jykpu

122. Gamble, C., Gowlett, J., \& Dunbar, R. (2011). The social brain and the shape of the Palaeolithic. Cambridge Archaeological Journal, 21(1), 115-135. doi:10.1017/S0959774311000072

123. Garofoli, D. (2014). Do early body ornaments prove cognitive modernity? A critical analysis from situated cognition. Phenomenology and the Cognitive Sciences, 14(4), 803-825. doi:10.1007/s11097-014-9356-0

124. Garofoli, D., \& lliopoulos, A. (2019). Replacing epiphenomenalism: a pluralistic enactive take on the metaplasticity of early body ornamentation. Philosophy \& Technology, 32, 215-242. doi:10.1007/s13347-017-0296-9

125. Gärdenfors, P., \& Högberg, A. (2017). The archaeology of teaching and the evolution of Homo docens. Current Anthropology, 58(2), 188-208. doi:10.1086/691178 
126. Geld, R. (2006). Konceptualizacija i vidovi konstruiranja značenja: temeljne kognitivnolingvističke postavke i pojmovi. Suvremena lingvistika, 62, 183-211https://hrcak.srce.hr/13494

127. Ghio, M., \& Tettamanti, M. (2016). Grounding sentence processing in the sensory-motor system. In G. Hickok \& S. L. Small (eds.), Neurobiology of Language (pp. 647-657). Amsterdam [etc.]: Academic Press. doi:10.1016/B978-0-12-407794-2.00052-3

128. Gianelli, C., Kühne, K., Presti, L., Mencaraglia, S., \& Dalla Volta, S., R (2020). Action processing in the motor system: Transcranial Magnetic Stimulation (TMS) evidence of shared mechanisms in the visual and linguistic modalities. Brain and Cognition, 139, 105510. doi:10.1016/j.bandc.2019.105510

129. Gibson, K. R. (2012). Tool-dependent foraging strategies and the origin of language. In K. R. Gibson \& M. Tallerman (eds.), The Oxford Handbook of Language Evolution (pp. 340-342). New York: Oxford University Press. doi:10.1093/oxfordhb/9780199541119.013.0035

130. Gifford-Gonzalez, D. (1993). You can hide, but you can't run: representations of women's work in illustrations of Palaeolithic life. Visual Anthropology Review, 9(1), 22-41.

doi:10.1525/var.1993.9.1.22

131. Glenberg, A. M., \& Kaschak, M. P. (2002). Grounding language in action. Psychonomic Bulletin \& Review, 9(3), 558-565. doi:10.3758/BF03196313

132. Goldman-Neuman, T., \& Hovers, E. (2009). Methodological considerations in the study of Oldowan raw material selectivity: insights from A. L. 894 (Hadar, Ethiopia). In E. Hovers \& D. R. Braun (eds.), Interdisciplinary Approaches to the Oldowan: Vertebrate Paleobiology and Paleoanthropology (pp. 71-84). Dordrecht: Springer. doi:10.1007/978-1-4020-9060-8_7

133. Goldman-Neuman, T., \& Hovers, E. (2012). Raw material selectivity in Late Pliocene Oldowan sites in the Makaamitalu Basin, Hadar, Ethiopia. Journal of Human Evolution, 62(3), 353-366. doi:10.1016/j.jhevol.2011.05.006

134. Gowlett, J., Gamble, C., \& Dunbar, R. (2012). Human evolution and the archaeology of the social brain. Current Anthropology, 53(6), 693-722. doi:10.1086/667994

135. Greenfield, P. M. (1991). Language, tools and brain: the ontogeny and phylogeny of hierarchically organized sequential behavior. Behavioral and Brain Sciences, 14, 531-595. doi:10.1017/S0140525X00071235

136. Grisoni, L., Dreyer, F. R., \& Pulvermüller, F. (2016). Somatotopic semantic priming and prediction in the motor system. Cerebral Cortex, 26(5), 2353-2366. doi:10.1093/cercor/bhw026

137. Grodzinsky, Y. (2000). The neurology of syntax: language use without Broca's area. Behavioral and Brain Sciences, 23(1), 1-71. doi:10.1017/s0140525x00002399

138. Groucutt, H. S., Scerri, E. M. L., Lewis, L., Clark-Balzan, L., Blinkhorn, J., Jennings, R. P., et al. (2015). Stone tool assemblages and models for the dispersal of Homo sapiens out of Africa. Quaternary International, 382, 8-30. doi:10.1016/j.quaint.2015.01.039

139. Hamrick, P., Lum, J. A. G., \& Ullman, M. T. (2018). Child first language and adult second language are both tied to general-purpose learning systems.Proceedings of the National Academy of Sciences of 
the United States of America, 115(7),1487-1492. doi:10.1073/pnas.1713975115

140. Harmand, S. (2009). Variability in raw material selectivity at the Late Pliocene sites of Lokalalei, West Turkana, Kenya. In E. Hovers \& D. R. Braun (eds.), Interdisciplinary Approaches to the Oldowan: Vertebrate Paleobiology and Paleoanthropology (pp. 85-97). Dordrecht: Springer. doi:10.1007/9781-4020-9060-8_8

141. Harmand, S., Lewis, J. E., Feibel, C. S., Lepre, C. J., Prat, S., Lenoble, A., et al. (2015). 3.3-million-yearold stone tools from Lomekwi 3, West Turkana, Kenya. Nature, 521, 310-315. doi:10.1038/nature14464

142. Harmand, S., Lewis, J. E., Taylor, N., Feiber, C. S., Boës, X., Prat, S., \& Roche, H. (2019). Reply to Domínguez-Rodrigo and Alcalá: interpretation without accurate evidence is fantasy. Journal of African Archaeology, 17(2), 177-181. doi:10.1163/21915784-20190007

143. Hauk, O. (2016). What does it mean? A review of the neuroscientific evidence for embodied lexical semantics. In G. Hickok \& S. L. Small (eds.), Neurobiology of Language (pp. 777-788). Amsterdam [etc.]: Academic Press. doi:10.1016/B978-0-12-407794-2.00062-6

144. Hauk, O., Johnsrude, I., \& Pulvermüller, F. (2004). Somatotopic representation of action words in human motor and premotor cortex. Neuron, 41(2), 301-307. doi:10.1016/S0896-6273(03)00838-9

145. Hauk, O., Shtyrov, Y., \& Pulvermüller, F. (2006). The sound of actions as reflected by mismatch negativity: rapid activation of cortical sensory-motor networks by sounds associated with finger and tongue movements. European Journal of Neuroscience, 23, 811-821. doi:10.1111/j.14609568.2006.04586.x

146. Hauser, O. (1921). Urmensch und Wilder: Eine Parallele aus Urwelttagen und Gegenwart. Berlin: Ullstein \& Co.

147. Heard, A., Madan, C. R., Protzner, A. B., \& Pexman, P. M. (2018). Getting a grip on sensorimotor effects in lexical-semantic processing. Behavior Research Methods, 51(1), 1-13. doi:10.3758/s13428-0181072-1

148. Hecht, E. E., Gutman, D. A., Khreisheh, N., Taylor, S. V., Kilner, J., et al. (2014). Acquisition of Paleolithic toolmaking abilities involves structural remodeling to inferior frontoparietal regions. Brain Structure and Function, 220(4), 2315-2331. doi:10.1007/s00429-014-0789-6

149. Henshilwood, C. S., \& Marean, C. W. (2003). The origin of modern human behavior: critique of the models and their test implications. Current Anthropology, 44(5), 627-651. doi:10.1086/377665

150. Herzlinger, G., Wynn, T., \& Goren-Inbar, N. (2017). Expert cognition in the production sequence of Acheulian cleavers at Gesher Benot Ya'aqov, Israel: a lithic and cognitive analysis. PLoS One, 12(11), e0188337. doi:10.1371/journal.pone.0188337

151. Hewlett, B. (2021). Social learning and innovation in adolescence. Human Nature (Online first articles). doi:10.1007/s12110-021-09391-y

152. Hoffmann, D. L., Standish, C. D., García-Diez, M., Pettitt, P. B., Milton, J. A., Zilhão, J., et al. (2018). UTh dating of carbonate crusts reveals Neandertal origin of Iberian cave art. Science, 359, 912-915. doi:10.1126/science.aap7778 
153. Hopkins, W. D., Meguerditchian, A., Coulon, O., Misiura, M., Pope, S., Mareno, M. C., \& Schapiro, S. J. (2017). Motor skill for tool-use is associated with asymmetries in Broca's area and the motor hand area of the precentral gyrus in chimpanzees (Pan troglodytes). Behavioural Brain Research, 318, 7181. doi:10.1016/j.bbr.2016.10.048

154. Hovers, E. (2015). Archaeology: tools go back in time. Nature, 521, 294-295. doi:10.1038/521294a

155. Hupfeld, K. E., Ketcham, C. J., \& Schneider, H. D. (2017). Transcranial direct current stimulation (tDCS) to Broca's area: persisting effects on non-verbal motor behaviors. Neurological Disorders and Therapeutics, 1(1), 1-5. doi:10.15761/NDT.1000102

156. Hurford, J. R. (2004). Language beyond our grasp: what mirror neurons can, and cannot, do for language evolution. In D. Kimbrough Oller \& U. Griebel (eds.), The Evolution of Communication Systems: A Comparative Approach (pp. 297-313). Cambridge: MIT Press

157. Inizan, M. L., Reduron-Ballinger, M., Roche, H., \& Tixier, J. (1999). Technology and Terminology of Knapped Stone. Nanterre: C.R.E.P.

158. Jackendoff, R. (1999). Possible stages in the evolution of the language capacity. Trends in Cognitive Sciences, 3(7), 272-279. doi:10.1016/S1364-6613(99)01333-9

159. Jackendoff, R., \& Wittenberg, E. (2014). What you can say without syntax: a hierarchy of grammatical complexity. In F. J. Newmeyer \& L. B. Preston (eds.), Measuring Grammatical Complexity (pp. 65-82). Oxford: Oxford University Press. doi:10.1093/acprof:oso/9780199685301.003.0004

160. JASP Team (2020). JASP (Version 0.13.1) [Computer software]. Retrieved from https://jaspstats.org/

161. Jöris, O., \& Uomini, N. (2019). Evidence for Neanderthal hand preferences from the late Middle Palaeolithic site of Buhlen, Germany: insights into Neanderthal learning behaviour. In Y. Nishiaki \& 0 . Jöris (eds.), Learning Among Neanderthals and Palaeolithic Modern Humans: Archaeological Evidence (pp. 77-94). Singapore: Springer. doi:10.1007/978-981-13-8980-1_6

162. Karakostis, F. A., Haeufle, D., Anastopoulou, I., Moraitis, K., Hotz, G., Tourloukis, V., \& Harvati, K. (2021). Biomechanics of the human thumb and the evolution of dexterity. Current Biology, 31(6), 13171325e8. doi:10.1016/j.cub.2020.12.041

163. Karakostis, F. A., \& Harvati, K. (2021). New horizons in reconstructing past human behavior: introducing the "Tübingen University Validated Entheses-based Reconstruction of Activity" method. Evolutionary Anthropology (Early View). doi:10.1002/evan.21892

164. Karavanić, I., Vukosavljević, N., Janković, I., Ahern, J. C. M., \& Smith, F. H. (2018). Paleolithic hominins and settlement in Croatia from MIS 6 to MIS 3: research history and current interpretations. Quaternary International, 494, 152-166. doi:10.1016/j.quaint.2017.09.034

165. Karavanić, I., Banda, M., Radović, S., Miko, S., Vukosavljević, N., Razum, I., \& Smith, F. H. (2021). A palaeoecological view of the last Neanderthals at the crossroads of south-central Europe and the central Mediterranean: Iong-term stability or pronounced environmental change with human responses. Journal of Quaternary Science (Early View). doi:10.1002/jqs.3279 
166. Keeley, L. H. (2010). The probable sexual division of labor in Magdalenian hide working: ethnological evidence. In E. Zubrow, F. Audouze, J. G. Enloe (eds.), The Magdalenian Household: Unraveling Domesticity (pp. 227-234). Albany: SUNY Press

167. Kellermann, T., Regenbogen, C., De Vos, M., Mößnang, C., Finkelmeyer, A., \& Habel, U. (2012). Effective connectivity of the human cerebellum during visual attention. Journal of Neuroscience, 32(33), 11453-11460. doi:10.1523/JNEUROSCI.0678-12.2012

168. Kemmerer, D. (2012). The cross-linguistic prevalence of SOV and SVO word order reflects the sequential and hierarchical representation of action in Broca's area. Language and Linguistics Compass, 6(1), 50-66. doi:10.1002/Inc3.322

169. Kemmerer, D. (2014). Word classes in the brain: implications of linguistic typology for cognitive neuroscience. Cortex, 58, 27-51. doi:10.1016/j.cortex.2014.05.004

170. Kemmerer, D. (2015). Does the motor system contribute to the perception and understanding of actions? Reflections on Gregory Hickok's The myth of mirror neurons: the real neuroscience of communication and cognition. Language and Cognition, 7, 450-475. doi:10.1017/langcog.2014.36

171. Key, A. J. M., \& Dunmore, C. J. (2018). Manual restrictions on Palaeolithic technological behaviours. PeerJ, 6, e5399. doi:10.7717/peerj.5399

172. Key, A. J., \& Lycett, S. J. (2018a). Investigating interrelationships between Lower Palaeolithic stone tool effectiveness and tool user biometric variation: implications for technological and evolutionary changes. Archaeological and Anthropological Sciences, 10, 989-1006. doi:10.1007/s12520-0160433-x

173. Key, A., Merritt, S. R., \& Kivell, T. L. (2018b). Hand grip diversity and frequency during the use of Lower Palaeolithic stone cutting-tools. Journal of Human Evolution, 125, 137-158. doi:10.1016/j.jhevol.2018.08.006

174. Key, A. J. M., Farr, I., Hunter, R., \& Winter, S. L. (2020). Muscle recruitment and stone tool use ergonomics across three million years of Palaeolithic technological transitions. Journal of Human Evolution, 144, 102796. doi:10.1016/j.jhevol.2020.102796

175. Kimura, Y. (1997). The MNK chert factory site: the chert-using strategy by early hominids at Olduvai Gorge, Tanzania. African Study Monographs, 18, 1-28http://hdl.handle.net/2433/68153

176. Kimura, Y. (1999). Tool-using strategies by early hominids at Bed II, Olduvai Gorge, Tanzania. Journal of Human Evolution, 37, 807-831. doi:10.1006/jhev.1999.0316

177. Kimura, Y. (2002). Examining time trends in the Oldowan technology at Beds I and II, Olduvai Gorge. Journal of Human Evolution, 43, 291-321. doi:10.1006/jhev.2002.0576

178. Kochiyama, T., Ogihara, N., Tanabe, H. C., Kondo, O., Amano, H., Hasegawa, K., et al. (2018). Reconstructing the Neanderthal brain using computational anatomy. Scientific Reports, 8, 6296. doi:10.1038/s41598-018-24331-0

179. Kolodny, O., \& Edelman, S. (2018). The evolution of the capacity for language: the ecological context and adaptive value of a process of cognitive hijacking. Philosophical Transactions of the Royal Society B: Biological Sciences, 373(1743), 20170052. doi:10.1098/rstb.2017.0052 
180. Krause, J., Lalueza-Fox, C., Orlando, L., Enard, W., Green, R. E., Burbano, H. A., et al. (2007). The derived FOXP2 variant of modern humans was shared with Neandertals. Current Biology, 17(21), 1908-1912. doi:10.1016/j.cub.2007.10.008

181. Kroliczak, G., Buchwald, M., Kleka, P., Klichowski, M., Potok, W., Nowik, A. M., et al. (2021). Manual praxis and language-production networks, and their links to handedness. Cortex. In Press. doi:10.1016/j.cortex.2021.03.022

182. Kunert, R., Willems, R. M., Casasanto, D., Patel, A. D., \& Hagoort, P. (2015). Music and language syntax interact in Broca's area: an fMRI study. PLoS One, 10(11), e0141069. doi:10.1371/journal.pone.0141069

183. Lancia, S., Cofini, V., Carrieri, M., Ferrari, M., \& Quaresima, V. (2018). Are ventrolateral and dorsolateral prefrontal cortices involved in the computerized Corsi block-tapping test execution? An fNIRS study. Neurophotonics, 5(1), 011019. doi:10.1117/1.NPh.5.1.011019

184. Lazeron, R. H. C., Rombouts, S. A. R. B., Machielsen, W. C. M., Scheltens, P., Witter, M. P., Uylings, H. B., \& Barkhof, F. (2000). Visualizing brain activation during planning: the Tower of London test adapted for functional MR imaging. American Journal of Neuroradiology, 21(8), 1407-

1414https://pubmed.ncbi.nlm.nih.gov/11003272/

185. Leakey, M. D. (1971). Olduvai Gorge, vol. 3: Excavations in Beds I and II, 1960-1963. Cambridge: Cambridge University Press

186. Leakey, M. D. (1975). Cultural patterns in the Olduvai sequence. In K. W. Butzer \& G. L. Isaac (eds.), After the Australopithecines: Stratigraphy, Ecology and Culture Change in the Middle Pleistocene (pp. 477-493). Chicago: Mouton Publishers. doi:10.1515/9783110878837.477

187. Levelt, W. J. M. (2018). Is language natural to man? Some historical considerations. Current Opinions in Behavioral Sciences, 21, 127-131. doi:10.1016/j.cobeha.2018.04.003

188. Lieberman, P. (2015). Language did not spring forth 100,000 years ago. PLoS Biology, 13(2), e1002064. doi:10.1371/journal.pbio.1002064

189. Lindly, J. M., \& Clark, G. A. (1990). Symbolism and modern human origins. Current Anthropology, 31(3), 233-261. doi:10.1086/203836

190. Liuzzi, A. G., Bruffaerts, R., Peeters, R., Adamczuk, K., Keuleers, E., De Deyne, S., et al. (2017). Crossmodal representation of spoken and written word meaning in left pars triangularis. Neuroimage, 150, 292-307. doi:10.1016/j.neuroimage.2017.02.032

191. Lombao, D., Guardiola, M., \& Mosquera, M. (2017). Teaching to make stone tools: new experimental evidence supporting a technological hypothesis for the origins of language. Scientific Reports, 7, 14394. doi:10.1038/s41598-017-14322-y

192. Lotem, A., Halpern, J. Y., Edelman, S., \& Kolodny, O. (2017). The evolution of cognitive mechanisms in response to cultural innovations. Proceedings of the National Academy of Sciences of the United States of America, 114(30), 7915-7922. doi:10.1073/pnas.1620742114

193. Luncz, L. V., Mundry, R., \& Boesch, C. (2012). Evidence for cultural differences between neighboring chimpanzee communities. Current Biology, 22, 922-926. doi:10.1016/j.cub.2012.03.031 
194. Lycett, S. J., \& Eren, M. I. (2018). Built-in misdirection: on the difficulties of learning to knap. Lithic Technology, 44(1), 8-21. doi:10.1080/01977261.2018.1539322

195. Mahaney, R. A. (2014). Exploring the complexity and structure of Acheulean stoneknapping in relation to natural language. PaleoAnthropology, 2014, 586-606. doi:10.4207/PA.2014.ART90

196. Majkić, A., d'Errico, F., \& Stepanchuk, V. (2018). Assessing the significance of Palaeolithic engraved cortexes: a case study from the Mousterian site of Kiik-Koba, Crimea. PLoS One, 13(5), e0195049. doi:10.1371/journal.pone.0195049

197. Maran, M., Numssen, O., Hartwigsen, G., Friederici, A. D., \& Zaccarella, E. (2021). Towards a causal role of Broca's area in language: a TMS-EEG study on syntactic prediction. [Preprint]. bioRxiv. doi:10.1101/2021.04.14.439631

198. Mariën, P., Ackermann, H., Adamaszek, M., Barwood, C. H. S., Beaton, A., Desmond, J., et al. (2014). Consensus paper: Language and the cerebellum: an ongoing enigma. Cerebellum, 13(3), 386-410. doi:10.1007/s12311-013-0540-5

199. Matasović, R. (2011). Jezična raznolikost svijeta: Podrijetlo, razvitak, izgledi. Zagreb: Algoritam 200. McDowell, T., Holmes, N. P., Sunderland, A., \& Schürmann, M. (2018). TMS over the supramarginal gyrus delays selection of appropriate grasp orientation during reaching and grasping tools for use. Cortex, 103, 117-129. doi:10.1016/j.cortex.2018.03.002

201. McHenry, L. J., \& de la Torre, I. (2018). Hominin raw material procurement in the Oldowan-Acheulean transition at Olduvai Gorge. Journal of Human Evolution, 120, 378-401. doi:10.1016/j.jhevol.2017.11.010

202. McMahon, A., \& McMahon, R. (2013). Evolutionary Linguistics. New York: Cambridge University Press. doi:10.1017/СB09780511989391

203. McPherron, S. P., Alemseged, Z., Marean, C. W., Wynn, J. G., Reed, D., Geraads, D., et al. (2010). Evidence for stone-tool-assisted consumption of animal tissues before 3.39 million years ago at Dikika, Ethiopia. Nature, 466, 857-860. doi:10.1038/nature09248

204. Meyer, G. F., Spray, A., Fairlie, J. E., \& Uomini, N. T. (2014). Inferring common cognitive mechanisms from brain blood-flow lateralization data: a new methodology for fTCD analysis. Frontiers in Psychology, 5, 552. doi:10.3389/fpsyg.2014.00552

205. Michlich, J. (2018). An analysis of semiotic and mimetic processes in Australopithecus afarensis. Public Journal of Semiotics, 8(2), 1-12. doi:10.37693/pjos.2018.8.18694

206. Miura, N., Nagai, K., Yamazaki, M., Yoshida, Y., Tanabe, H. C., Akazawa, T., \& Sadato, N. (2014). Brain activation related to the imitative learning of bodily actions observed during the construction of a Mousterian stone tool: a functional magnetic resonance imaging study. In T. Akazawa, N. Ogihara, $\mathrm{H}$. C. Tanabe, H. Terashima (eds.), Dynamics of Learning in Neanderthals and Modern Humans Volume 2: Cognitive and Physical Perspectives (pp. 221-232). Tokyo: Springer. doi:10.1007/978-4-43154553-8_26

207. Mollo, G., Pulvermüller, F., \& Hauk, O. (2016). Movement priming of EEG/MEG brain responses for action-words characterizes the link between language and action. Cortex, 74, 262-276. 
doi:10.1016/j.cortex.2015.10.021

208. Moore, M. W. (2010). "Grammars of action” and stone flaking design space. In A. Nowell \& I.

Davidson (eds.), Stone Tools and the Evolution of Human Cognition (pp. 13-43). Boulder: University Press of Colorado

209. Moore, M. W. (2011). The design space of stone flaking: implications for cognitive evolution. World Archaeology, 43(4), 702-715. doi:10.1080/00438243.2011.624778

210. Moore, M. W., \& Perston, Y. (2016). Experimental insights into the cognitive significance of early stone tools. PLoS One, 11(7), e0158803. doi:10.1371/journal.pone.0158803

211. Morgan, T. J. H., Uomini, N. T., Rendell, L. E., Chouinard-Thuly, L., Street, S. E., Lewis, H. M., et al. (2015). Experimental evidence for the co-evolution of hominin tool-making teaching and language. Nature Communications, 6, 6029. doi:10.1038/ncomms7029

212. Mueller, S. T. (2012). The Psychology Experiment Building Language, Version 0.13. Retrieved from http://pebl.sourceforge.net

213. Mueller, S. T., \& Piper, B. J. (2014). The Psychology Experiment Building Language (PEBL) and PEBL Test Battery. Journal of Neuroscience Methods, 222, 250-259. doi:10.1016/j.jneumeth.2013.10.024

214. Mufwene, S. S. (2018). "Socio-cultural transmission" in language evolution? Physics of Life Reviews, 26-27, 155-157. doi:10.1016/j.plrev.2018.06.015

215. Muller, A., Clarkson, C., \& Shipton, C. (2017). Measuring behavioural and cognitive complexity in lithic technology throughout human evolution. Jorunal of Anthropological Archaeology, 48, 166-180. doi:10.1016/j.jaa.2017.07.006

216. Nishiaki, Y. (2019). Mastering hammer use in stone knapping: an experiment. In Y. Nishiaki \& O. Jöris (eds.), Learning Among Neanderthals and Palaeolithic Modern Humans: Archaeological Evidence (pp. 59-76). Singapore: Springer. doi:10.1007/978-981-13-8980-1_5

217. Nonaka, T., Bril, B., \& Rein, R. (2010). How do stone knappers predict and control the outcome of flaking? Implications for understanding early stone tool technology. Journal of Human Evolution, 59, 155-167. doi:10.1016/j.jhevol.2010.04.006

218. Normile, D. (2012). Evolution of language: experiments probe language's origins and development. Science, 336, 408-411. doi:10.1126/science.336.6080.408

219. Novén, M., Schremm, A., Nilsson, M., Horne, M., \& Roll, M. (2019). Cortical thickness of Broca's area and right homologue is related to grammar learning aptitude and pitch discrimination proficiency. Brain and Language, 188, 42-47. doi:10.1016/j.bandl.2018.12.002

220. Nowell, A., \& Davidson, I. (Eds.). (2010). Stone Tools and the Evolution of Human Cognition. Boulder: University Press of Colorado

221. Numssen, O., Bzdok, D., \& Hartwigsen, G. (2021). Functional specialization within the inferior parietal lobes across cognitive domains. ELife, 10, e63591. doi:10.7554/elife.63591

222. Ohnuma, K., Aoki, K., \& Akazawa, T. (1997). Transmission of tool-making through verbal and nonverbal communication: preliminary experiments in Levallois flake production. Anthropological 
Science, 105(3), 159-168. doi:10.1537/ase.105.159

223. Oldfield, R. C. (1971). The assessment and analysis of handedness: the Edinburgh inventory. Neuropsychologia, 9, 97-113. doi:10.1016/0028-3932(71)90067-4

224. Osiurak, F., Lesourd, M., Navarro, J., \& Reynaud, E. (2020). Technition: when tools come out of the closet. Perspectives on Psychological Science, 15(4), 880-897. doi:10.1177/1745691620902145

225. Osuna-Mascaró, A. J., Ortiz, C., Stolz, C., Musgrave, S., Sanz, C. M., Morgan, D. B., \& Fragaszy, D. M. (2020). Dexterity and technique in termite fishing by chimpanzees (Pan troglodytes troglodytes) in the Goualougo Triangle, Republic of Congo. American Journal of Primatology, 83(1), e23215. doi:10.1002/ajp.23215

226. Overmann, K. A., \& Wynn, T. (2018). Materiality and human cognition. Journal of Archaeological Method and Theory, 26, 457-478. doi:10.1007/s10816-018-9378-y

227. Overmann, K. A., \& Coolidge, F. L. (2019). Squeezing Minds From Stones: Cognitive Archaeology and the Evolution of the Human Mind. New York: Oxford University Press. doi:10.1093/oso/9780190854614.001.0001

228. Pagel, M. (2017). Q\&A: What is human language, when did it evolve and why should we care? BMC Biology, 15(1), 64. doi:10.1186/s12915-017-0405-3

229. Pain, R. (2021). What can the lithic record tell us about the evolution of hominin cognition? Topoi, 40, 245-259. doi:10.1007/s11245-019-09683-0

230. Palmer, M., Gildea, D., \& Xue, N. (2009). Semantic Role Labeling. Morgan \& Claypool. doi:10.2200/S00239ED1V01Y200912HLT006

231. Pante, M. C., \& de la Torre, I. (2018). A hidden treasure of the Lower Pleistocene at Olduvai Gorge, Tanzania: the Leakey HWK EE assemblage. Journal of Human Evolution, 120, 114-139. doi:10.1016/j.jhevol.2017.06.006

232. Parravicini, A., \& Pievani, T. (2019). Mosaic evolution in hominin phylogeny: meanings, implications, and explanations. Journal of Anthropological Sciences, 97, 45-68. doi:10.4436/JASS. 97001

233. Peti-Stantić, A., Anđel, M., Keresteš, G., Ljubešić, N., Stanojević, M. M., \& Tonković, M. (2018). Psycholinguistic estimates of 3000 words of Croatian: concreteness and imageability. Suvremena lingvistika, 44(85), 91-112. doi:10.22210/suvlin.2018.085.05

234. Peti-Stantić, A., Stanojević, M. M., Anđel, M., Tonković, M., Keresteš, G., Ljubešić, N., et al. (2019). Hrvatska psiholingvistička baza [Data set]. Modeliranje mentalne gramatike hrvatskoga: ograničenja informacijske strukture. doi:10.17234/megahr.2019.hpb

235. Peti-Stantić, A., Anđel, M., Gnjidić, V., Keresteš, G., Ljubešić, N., Masnikosa, et al. (2021). The Croatian psycholinguistic database: estimates for 6000 nouns, verbs, adjectives and adverbs. Behavior Research Methods (Online first articles). doi:10.3758/s13428-020-01533-x

236. Petruck, M. R. L. (1996). Frame semantics. In Östman, J. O., \& Verschueren, J. (Eds.), Handbook of Pragmatics. Amsterdam: John Benjamins. doi:10.1075/hop.2.fra1 
237. Piper, B. J., Li, V., Eiwaz, M. A., Kobel, Y. V., Benice, T. S., Chu, A. M., et al. (2012). Executive function on the Psychology Experiment Building Language tests. Behavior Research Methods, 44, 110-123. doi:10.3758/s13428-011-0096-6

238. Piper, B., Mueller, S. T., Talebzadeh, S., \& Ki, M. J. (2016). Evaluation of the validity of the Psychology Experiment Building Language tests of vigilance, auditory memory, and decision making. PeerJ, 4, e1772. doi:10.7717/peerj.1772

239. Planer, R. J. (2017). How language couldn't have evolved: a critical examination of Berwick and Chomsky's theory of language evolution. Biology \& Philosophy, 32, 779-796. doi:10.1007/s10539017-9606-y

240. Poldrack, R. A. (2006). Can cognitive processes be inferred from neuroimaging data? Trends in Cognitive Sciences, 10(2), 59-63. doi:10.1016/j.tics.2005.12.004

241. Prévost, M., Groman-Yaroslavski, I., Gershtein, C., Tejero, K. M., \& Zaidner, J. M., Y (2021). Early evidence for symbolic behavior in the Levantine Middle Paleolithic: a 120 ka old engraved aurochs bone shaft from the open-air site of Nesher Ramla, Israel. Quaternary International. In Press. doi:10.1016/j.quaint.2021.01.002

242. Proffitt, T. (2018). Is there a Developed Oldowan A at Olduvai Gorge? A diachronic analysis of the Oldowan in Bed I and Lower-Middle Bed II at Olduvai Gorge, Tanzania. Journal of Human Evolution, 120, 92-113. doi:10.1016/j.jhevol.2018.01.006

243. Progovac, L. (2015). Evolutionary Syntax. Oxford: Oxford University Press. doi:10.1093/acprof:oso/9780198736547.001.0001

244. Progovac, L. (2016). A gradualist scenario for language evolution: precise linguistic reconstruction of early human (and Neandertal) grammars. Frontiers in Psychology, 7, 1714. doi:10.3389/fpsyg.2016.01714

245. Progovac, L., Rakhlin, N., Angell, W., Liddane, R., Tang, L., \& Ofen, N. (2018). Diversity of grammars and their diverging evolutionary and processing paths: evidence from functional MRI study of Serbian. Frontiers in Psychology, 9, 278. doi:10.3389/fpsyg.2018.00278

246. Pruetz, J. D., \& Bertolani, P. (2007). Savanna chimpanzees, Pan troglodytes verus, hunt with tools. Current Biology, 17(5), 412-417. doi:10.1016/j.cub.2006.12.042

247. Pulvermüller, F. (2013). How neurons make meaning: brain mechanisms for embodied and abstractsymbolic semantics. Trends in Cognitive Sciences, 17(9), 458-470. doi:10.1016/j.tics.2013.06.004

248. Pulvermüller, F. (2018). Neural reuse of action perception circuits for language, concepts and communication. Progress in Neurobiology, 160, 1-44. doi:10.1016/j.pneurobio.2017.07.001

249. Pulvermüller, F., Hauk, O., Nikulin, V. V., \& Ilmoniemi, R. J. (2005). Functional links between motor and language systems. European Journal of Neuroscience, 21, 793-797. doi:10.1111/j.14609568.2005.03900.x

250. Pulvermüller, F., \& Fadiga, L. (2010). Active perception: sensorimotor circuits as a cortical basis for language. Nature Reviews Neuroscience, 11, 351-360. doi:10.1038/nrn2811 
251. Putt, S. S., Woods, A. D., \& Franciscus, R. G. (2014). The role of verbal interaction during experimental bifacial stone tool manufacture. Lithic Technology, 39(2), 96-112.

doi:10.1179/0197726114Z.00000000036

252. Putt, S. S., Wijeakumar, S., Franciscus, R. G., \& Spencer, J. P. (2017). The functional brain networks that underlie Early Stone Age tool manufacture. Nature Human Behaviour, 1, 0102. doi:10.1038/s41562-017-0102

253. Putt, S. S., \& Wijeakumar, S. (2018). Tracing the evolutionary trajectory of verbal working memory with neuro-archaeology. Interaction Studies, 19(1-2), 272-288. doi:10.1075/is.17042.put

254. Radovčić, D., Oros Sršen, A., Radovčić, J., \& Frayer, D. W. (2015). Evidence for Neandertal jewelry: modified white-tailed eagle claws at Krapina. PLoS One, 10(3), e0119802.

doi:10.1371/journal.pone.0119802

255. Reilly, J., Westbury, C., Kean, J., \& Peelle, J. E. (2012). Arbitrary symbolism in natural language revisited: when word forms carry meaning. PLoS One, 7(8), e42286.

doi:10.1371/journal.pone.0042286

256. Révész, G. (1946). Ursprung und Vorgeschichte der Sprache. Bern: A. Francke AG

257. Riel-Salvatore, J., \& Clark, G. A. (2001). Grave markers: Middle and Early Upper Paleolithic burials and the use of chronotypology in contemporary Paleolithic research. Current Anthropology, 42(4), 449479. doi:10.1086/321801

258. Rigaud, S., d'Errico, F., Vanhaeren, M., \& Neumann, C. (2009). Critical reassessment of putative Acheulean Porosphaera globularis beads. Journal of Archaeological Science, 36, 25-34. doi:10.1016/j.jas.2008.07.001

259. Rizzolatti, G., \& Craighero, L. (2004). The mirror-neuron system. Annual Review of Neuroscience, 27, 169-192. doi:10.1146/annurev.neuro.27.070203.144230

260. Roebroeks, W., Sier, M. J., Nielsen, T. K., De Loecker, D., Parés, J. M., Arps, C. E. S., \& Mücher, H. J. (2012). Use of red ochre by early Neandertals. Proceedings of the National Academy of Science of the United States of America, 109(6), 1889-1894. doi:10.1073/pnas.1112261109

261. Rolland, N., \& Dibble, H. L. (1990). A new synthesis of Middle Paleolithic variability. American Antiquity, 55(3), 480-499. doi:10.2307/281279

262. Rosenzopf, H., Wiesen, D., Basilakos, A., Yourganov, G., Bonilha, L., Rorden, C., et al. (2020). Mapping the human praxis network: an investigation of white matter disconnection in limb apraxia [Preprint]. bioRxiv. doi:10.1101/2020.04.14.041442

263. Rossano, M. J. (2017). Cognitive fluidity and Acheulean over-imitation. Cambridge Archaeological Journal, 27(3), 495-509. doi:10.1017/S0959774317000208

264. Ruck, L. (2014). Manual praxis in stone tool manufacture: implications for language evolution. Brain and Language, 139, 68-83. doi:10.1016/j.bandl.2014.10.003

265. Saeed, J. I. (1997). Semantics. Oxford: Blackwell Publishers 
266. Sahnouni, M. (2002). Further research at the Oldowan site of Ain Hanech, Northeastern Algeria. Journal of Human Evolution, 43, 925-937. doi:10.1006/jhev.2002.0608

267. Sahnouni, M., Schick, K., \& Toth, N. (1997). An experimental investigation into the nature of faceted limestone "spheroids" in the Early Palaeolithic. Journal of Archaeological Science, 24, 701-713. doi:10.1006/jasc.1996.0152

268. Sahnouni, M., \& de Heinzelin, J. (1998). The site of Ain Hanech revisited: new investigations at this Lower Pleistocene site in Northern Algeria. Journal of Archaeological Science, 25, 1083-1101. doi:10.1006/jasc.1998.0278

269. Sassaman, K. E. (1993). Lithic technology and the hunter-gatherer sexual division of labor. North American Archaeologist, 13(3), 249-262. doi:10.2190/K1PN-3X1H-60W6-PLNC

270. Schamberg, I., Cheney, D. L., \& Seyfarth, R. M. (2017). Bonobos (Pan paniscus) perform branch drag displays before long-distance travel. International Journal of Primatology, 38, 500-512. doi:10.1007/s10764-017-9957-x

271. Schick, K., \& Toth, N. (2006). An overview of the Oldowan Industrial Complex: the sites and the nature of their evidence. In N. Toth \& K. Schick (eds.), The Oldowan: Case Studies into the Earliest Stone Age (pp. 3-42). Gosport: Stone Age Institute Press

272. Schlanger, N. (1996). Understanding Levallois: lithic technology and cognitive archaeology. Cambridge Archaeological Journal, 6(2), 231-254. doi:10.1017/S0959774300001724

273. Schween, R., Taylor, J. A., \& Hegele, M. (2018). Plan-based generalization shapes local implicit adaptation to opposing visuomotor transformations. Journal of Neurophysiology, 120(6), 27752787. doi:10.1152/jn.00451.2018

274. Semaw, S. (2000). The world's oldest stone artefacts from Gona, Ethiopia: their implications for understanding stone technology and patterns of human evolution between 2.6-1.5 million years ago. Journal of Archaeological Science, 27, 1197-1214. doi:10.1006/jasc.1999.0592

275. Semaw, S. (2006). The oldest stone artifacts from Gona (2.6-2.5 Ma), Afar, Ethiopia: implications for understanding the earliest stages of stone knapping. In N. Toth \& K. Schick (eds.), The Oldowan: Case Studies into the Earliest Stone Age (pp. 43-75). Gosport: Stone Age Institute Press

276. Semaw, S., Renne, P., Harris, J. W. K., Feibel, C. S., Bernor, R. L., Fesseha, N., \& Mowbray, K. (1997). 2.5million-year-old stone tools from Gona, Ethiopia. Nature, 385, 333-336. doi:10.1038/385333a0

277. Semaw, S., Rogers, M. J., Quade, J., Renne, P. R., Butler, R. F., Dominguez-Rodrigo, M., et al. (2003). 2.6-million-year-old stone tools and associated bones from OGS-6 and OGS-7, Gona, Afar, Ethiopia. Journal of Human Evolution, 45, 169-177. doi:10.1016/S0047-2484(03)00093-9

278. Semaw, S., Simpson, S. W., Quade, J., Renne, P. R., Butler, R. F., McIntosh, W. C., et al. (2005). Early Pliocene hominids from Gona, Ethiopia. Nature, 433, 301-305. doi:10.1038/nature03177

279. Semaw, S., Rogers, M., \& Stout, D. (2009). The Oldowan-Acheulian transition: is there a "Developed Oldowan" artifact tradition?. In M. Camps \& P. Chauhan (eds.), Sourcebook of Paleolithic Transitions (pp. 173-193). New York: Springer. doi:10.1007/978-0-387-76487-0_10 
280. Semaw, S., Rogers, M. J., Simpson, S. W., Levin, N. E., Quade, J., Dunbar, N., et al. (2020). Cooccurrence of Acheulian and Oldowan artifacts with Homo erectus cranial fossils from Gona, Afar, Ethiopia. Science Advances, 6(10), eaaw4694. doi:10.1126/sciadv.aaw4694

281. Shea, J. J. (2020). Prehistoric Stone Tools of Eastern Africa: A Guide. Cambridge: Cambridge University Press. doi:10.1017/9781108334969

282. Shimelmitz, R., \& Kuhn, S. L. (2018). The toolkit in the core: there is more to Levallois production than predetermination. Quaternary International, 464, 81-91. doi:10.1016/j.quaint.2017.08.011

283. Spike, M. (2017). The evolution of linguistic rules. Biology \& Philosophy, 32(6), 887-904. doi:10.1007/s10539-018-9610-x

284. Spott, E. (2005). Analysis of quartz in Northern Wisconsin: deficiencies, misconceptions and goals. Nebraska Anthropologist, 20, 115-128https://digitalcommons.unl.edu/nebanthro/10/

285. Steele, J., \& Uomini, N. (2009). Can the archaeology of manual specialization tell us anything about language evolution? A survey of the state of play. Cambridge Archaeological Journal, 19(1), 97-110. doi:10.1017/S0959774309000067

286. Stiles, D. N., Hay, R. L., \& O’Neil., J. R. (1974). The MNK Chert Factory Site, Olduvai Gorge, Tanzania. World Archaeology, 5, 285-308. doi:10.1080/00438243.1974.9979575

287. Stout, D. (2010). Possible relations between language and technology in human evolution. In A. Nowell \& I. Davidson (eds.), Stone Tools and the Evolution of Human Cognition (pp. 159-184). Colorado: Colorado University Press

288. Stout, D. (2011). Stone toolmaking and the evolution of human culture and cognition. Philosophical Transactions of the Royal Society B: Biological Sciences, 266, 1050-1059. doi:10.1098/rstb.2010.0369

289. Stout, D., Toth, N., Schick, K., Stout, J., \& Hutchins, G. (2000). Stone tool-making and brain activation: position emission tomography (PET) studies. Journal of Archaeological Science, 27, 1215-1223. doi:10.1006/jasc.2000.0595

290. Stout, D., \& Chaminade, T. (2007). The evolutionary neuroscience of tool making. Neuropsychologia, 45, 1091-1100. doi:10.1016/j.neuropsychologia.2006.09.014

291. Stout, D., Toth, N., Schick, K., \& Chaminade, T. (2008). Neural correlates of Early Stone Age toolmaking: technology, language and cognition in human evolution. Philosophical Transactions of the Royal Society Lond B: Biological Sciences, 363, 1939-1949. doi:10.1098/rstb.2008.0001

292. Stout, D., Passingham, R., Frith, C., Apel, J., \& Chaminade, T. (2011). Technology, expertise and social cognition in human evolution. European Journal of Neuroscience, 33, 1328-1338. doi:10.1111/j.1460-9568.2011.07619.x

293. Stout, D., \& Chaminade, T. (2012). Stone tools, language and the brain in human evolution. Philosophical Transactions of the Royal Society Lond B: Biological Sciences, 367(1585), 75-87. doi:10.1098/rstb.2011.0099

294. Stout, D., \& Hecht, E. (2015). Neuroarchaeology. In E. Bruner (ed.), Human Paleoneurology (pp. 145175). Cham: Springer. doi:10.1007/978-3-319-08500-5_7 
295. Stout, D., \& Khreisheh, N. (2015). Skill learning and human brain evolution: an experimental approach. Cambridge Archaeological Journal, 25(4), 867-875. doi:10.1017/S0959774315000359

296. Sumitani, S., Tanaka, T., Tayoshi, S., Ota, K., Kameoka, N., Ueno, S., \& Ohmori, T. (2006). Activation of the prefrontal cortex during the Wisconsin Card Sorting Test as measured by multichannel nearinfrared spectroscopy. Neuropsychobiology, 53(2), 70-76. doi:10.1159/000091722

297. Sumner, T. A. (2011). Psychological components of middle paleolithic technology: the proceduralization of lithic core reduction. Journal of Anthropological Archaeology, 30, 416-431. doi:10.1016/j.jaa.2011.04.003

298. Susman, R. L. (1991). Who made the Oldowan tools? Fossil evidence for tool behavior in PlioPleistocene hominids. Journal of Anthropological Research, 42(2), 129-151. doi:10.1086/jar.47.2.3630322

299. Tate, M. C., Herbert, G., Moritz-Gasser, S., Tate, J. E., \& Duffau, H. (2014). Probabilistic map of critical functional regions of the human cerebral cortex: Broca's area revisited. Brain, 137, 2773-2782. doi:10.1093/brain/awu168

300. Tattersall, I. (2019). The Minimalist Program and the origin of language: a view from paleoanthropology. Frontiers in Psychology, 10, 677. doi:10.3389/fpsyg.2019.00677

301. Tennie, C., Premo, L. S., Braun, D. R., \& McPherron, S. P. (2017). Early stone tools and cultural transmission: resetting the null hypothesis. Current Anthropology, 58(5), 652-672. doi:10.1086/693846

302. Tettamanti, M., Buccino, G., Saccuman, M. C., Gallese, V., Danna, M., Scifo, P., et al. (2005). Listening to action-related sentences activates fronto-parietal motor circuits. Journal of Cognitive Neuroscience, 17(2), 273-281. doi:10.1162/0898929053124965

303. Toth, N. (1985). The Oldowan reassessed: a close look at early stone artifacts. Journal of Archaeological Science, 12, 101-120. doi:10.1016/0305-4403(85)90056-1

304. Toth, N. (1987). The first technology. Scientific American, 256(4), 104-113. doi:10.1038/scientificamerican0487-112

305. Toth, N., \& Schick, K. (2009). The importance of actualistic studies in Early Stone Age research: some personal reflections. In K. Schick \& N. Toth (eds.), The Cutting Edge: New Advances into the Archaeology of Human Origins (pp. 267-344). Gosport: Stone Age Institute Press

306. Toth, N., \& Schick, K. (2018). An overview of the cognitive implications of the Oldowan Industrial Complex. Azania: Archaeological Research in Africa, 53(1), 3-39. doi:10.1080/0067270X.2018.1439558

307. Toya, G., \& Hashimoto, T. (2018). Recursive combination has adaptability in diversifiability of production and material culture. Frontiers in Psychology, 9, 1512. doi:10.3389/fpsyg.2018.01512

308. Troyer, A. K., Moscovitch, M., \& Winocur, G. (1997). Clustering and switching as two components of verbal fluency: evidence from younger and older healthy adults. Neuropsychology, 11(1), 138-146. doi:10.1037//0894-4105.11.1.138 
309. Trujillo, C. A., Rice, E. S., Schaefer, N. K., Chaim, I. A., Wheeler, E. C., Madrigal, A. A., et al. (2021). Reintroduction of the archaic variant of NOVA1 in cortical organoids alters neurodevelopment. Science, 371(6530), eaax2537. doi:10.1126/science.aax2537

310. Tumler, D., Basell, L., \& Coward, F. (2017). Human perception of symmetry, raw material and size of Palaeolithic handaxes. Lithics: the Journal of the Lithic Studies Society, 38, 517http://journal.lithics.org/index.php/lithics/article/view/720

311. Tuniz, C., Bernardini, F., Turk, I., Dimkaroski, L., Mancini, L., \& Dreossi, D. (2012). Did Neanderthals play music? X-ray computed micro-tomography of the Divje Babe 'flute'. Archaeometry, 54(3), 581590. doi:10.1111/j.1475-4754.2011.00630.x

312. Turk, I., Dirjec, J., Bastiani, G., Pflaum, M., Lauko, T., Cimerman, F., et al. (2001). New analyses of the "flute" from Divje babe I (Slovenia). Arheološki vestnik, 52, 25-79https://ojs.zrcsazu.si/av/article/view/8307

313. Tyler, L. K., Marslen-Wilson, W. D., Randall, B., Wright, P., Devereux, B. J., Zhuang, J., et al. (2011). Left inferior frontal cortex and syntax: function, structure and behaviour in patients with left hemisphere damage. Brain, 134, 415-431. doi:10.1093/brain/awq369

314. Uomini, N. (2015). Paleoneurology and behaviour. In E. Bruner (ed.), Human Paleoneurology (pp. 121-143). Cham: Springer. doi:10.1007/978-3-319-08500-5_6

315. Uomini, N. (2017). Neuroarchaeology: language and tools in the brain. Nature Human Behaviour, 1 , 0114. doi:10.1038/s41562-017-0114

316. Uomini, N. T., \& Meyer, G. F. (2013). Shared brain lateralization patterns in language and Acheulean stone tool production: a functional transcranial Doppler ultrasound study. PLoS One, 8(8), e72693. doi:10.1371/journal.pone.0072693

317. Uomini, N. T., \& Ruck, L. (2018). Manual laterality and cognition through evolution: an archeological perspective. Progress in Brain Research, 238, 295-323. doi:10.1016/bs.pbr.2018.06.015

318. Vaesen, K. (2012). The cognitive bases of human tool use. Behavioral and Brain Sciences, 35(4), 203-218. doi:10.1017/S0140525X11001452

319. Valdois, S., Carbonnel, S., Juphard, A., Baciu, M., Ans, B., Peyrin, C., \& Segebarth, C. (2006). Polysyllabic pseudo-word processing in reading and lexical decision: converging evidence from behavioral data, connectionist simulations and functional MRI. Brain Research, 1085(1), 149-162. doi:10.1016/j.brainres.2006.02.049

320. van Dam, W. O., \& Desai, R. H. (2016). The semantics of syntax: the grounding of transitive and intransitive constructions. Journal of Cognitive Neuroscience, 28(5), 693-709. doi:10.1162/jocn_a_00926

321. Vandervert, L. (2018). How prediction based on sequence detection in the cerebellum led to the origins of stone tools, language, and culture, and, thereby, to the rise of Homo sapiens. Frontiers in Cellular Neuroscience, 12, 408. doi:10.3389/fncel.2018.00408

322. Vandervert, L. (2020). The prominent role of the cerebellum in the social learning of the phonological loop in working memory: how language was adaptively built from cerebellar inner speech required 
during stone-tool making. AIMS Neuroscience, 7(3), 333-343. doi:10.3934/Neuroscience.2020020

323. Vigneau, M., Beaucousin, V., Hervé, P. Y., Jobard, G., Petit, L., Crivello, F., et al. (2011). What is righthemisphere contribution to phonological, lexico-semantic, and sentence processing? Insights from a meta-anaylsis. Neurolmage, 54, 577-593. doi:10.1016/j.neuroimage.2010.07.036

324. Waguespack, N. M. (2005). The organization of male and female labor in foraging societies: implications for Early Paleoindian archaeology. American Anthropologist, 107(4), 666-676. doi:10.1525/aa.2005.107.4.666

325. Watts, I. (2009). Red ochre, body painting, and language: interpreting the Blombos ochre. In R. Botha \& C. Knight (eds.), The Cradle of Language (pp. 62-92). New York: Oxford University Press

326. Willems, R. M., Hagoort, P., \& Casasanto, D. (2010). Body-specific representations of action verbs: neural evidence from right- and left-handers. Psychological Science, 21, 67-74. doi:10.1177/0956797609354072

327. Willoughby, P. R. (1985). Spheroids and battered stones in the African Early Stone Age. World Archaeology, 17, 44-60. doi:10.1080/00438243.1985.9979949

328. Wittenburg, P., Brugman, H., Russel, A., Klassmann, A., \& Sloetjes, H. (2006). ELAN: a professional framework for multimodality research. In N. Calzolari, K. Choukri, A. Gangemi, B. Maegaard, J. Mariani, J. Odijk, D. Tapias(eds.), Proceedings of the Fifth International Conference on Language Resources and Evaluation (LREC'06) (pp. 1556-1559). Genoa: European Language Resources Association (ELRA). http://www.Irec-conf.org/proceedings/Irec2006/pdf/153_pdf.pdf

329. Wong, S. T. S., Goghari, V. M., Sanford, N., Lim, R., Clark, C., Metzak, P. D., et al. (2020). Functional brain networks involved in lexical decision. Brain and Cognition, 138, 103631. doi:10.1016/j.bandc.2019.103631

330. Wright, S. K. (2002). Transitivity and change of state verbs. In J. Larson \& M. Paster (eds.), Proceedings of the Twenty-Eighth Annual Meeting of the Berkeley Linguistics Society: General Session and Parasession on Field Linguistics (pp. 339-350). Berkeley: Berkeley Linguistics Society. doi:10.3765/bls.v28i1.3849

331. Wynn, T., \& Coolidge, F. L. (2011). The implications of the working memory model for the evolution of modern cognition. International Journal of Evolutionary Biology, 2011, 741357. doi:10.4061/2011/741357

332. Wynn, T., \& Coolidge, F. L. (2016). Archeological insights into hominin cognitive evolution. Evolutionary Anthropology, 25, 200-213. doi:10.1002/evan.21496

333. Wynn, T., \& Gowlett, J. (2018). The handaxe reconsidered. Evolutionary Anthropology, 27, 21-29. doi:10.1002/evan.21552

334. Zaidner, Y., Centi, L., Prevost, M., Shemer, M., \& Varoner, O. (2018). An open-air site at Nesher Ramla, Israel, and new insights into Levantine Middle Paleolithic technology and site use. In Y. Nishiaki \& T. Akazawa (eds.), The Middle and Upper Paleolithic Archeology of the Levant and Beyond: Replacement of Neanderthals by Modern Humans Series (pp. 11-33). Singapore: Springer. doi:10.1007/978-981-10-6826-3_2 
335. Zilhão, J., Angelucci, D. E., Badal-García, E., d’Errico, F., Daniel, F., Dayet, L., et al. (2010). Symbolic use of marine shells and mineral pigments by Iberian Neandertals. Proceedings of the National Academy of Sciences of the United States of America, 107(3), 1023-1028. doi:10.1073/pnas.0914088107

\section{Figures}

\section{Figure 1}

Tools made by the subjects during the experiment: 1) example of a well-made chopper, 2) example of a poorly made chopper, 3) example of a well-made scraper, 4) example of a poorly made scraper. The wellmade chopper has two contiguous flake scars that form a continuous sharp edge, as opposed to the poorly made example whose edge is almost perpendicular to the surface of the pebble. On the other hand, the well-made scraper is a large and clearly identifiable flake with a continuous semi-steep retouched edge (the retouch scars are large and well-spaced), whilst the poorly made scraper is not a flake per se, but a thin chip with no unambiguous knapping attributes (i.e., bulb of percussion and platform) and a retouched edge with shallow and short scars, more reminiscent of edge damage than true retouch. Photo: MB 
a)
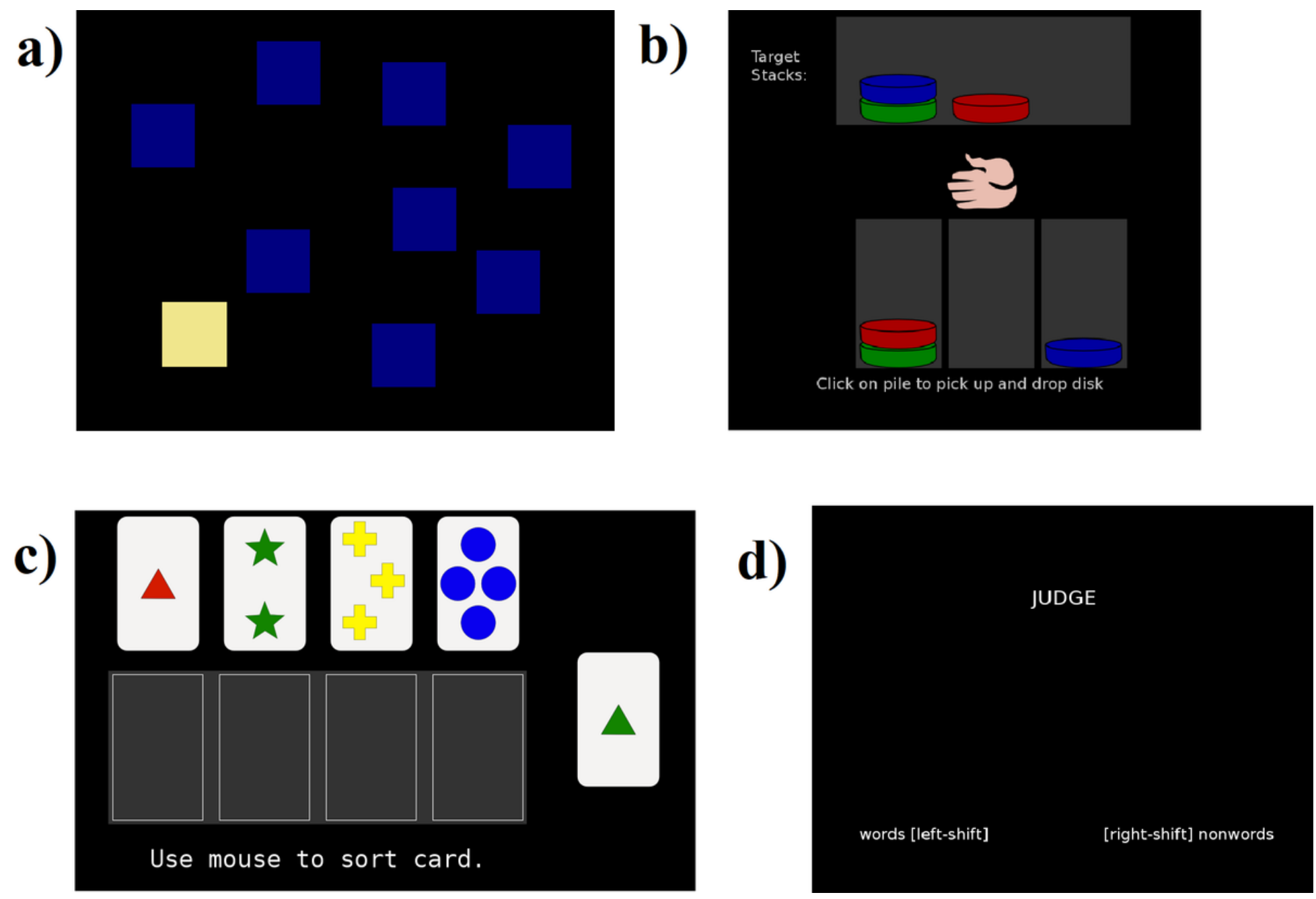

\section{Figure 2}

Screenshots from the individual PEBL tasks (presented under the General Public License). a) Corsi Blocktapping Test, b) Tower of London, c) Wisconsin Card Sorting Test, d) lexical decision 


\section{What can one do at home?}

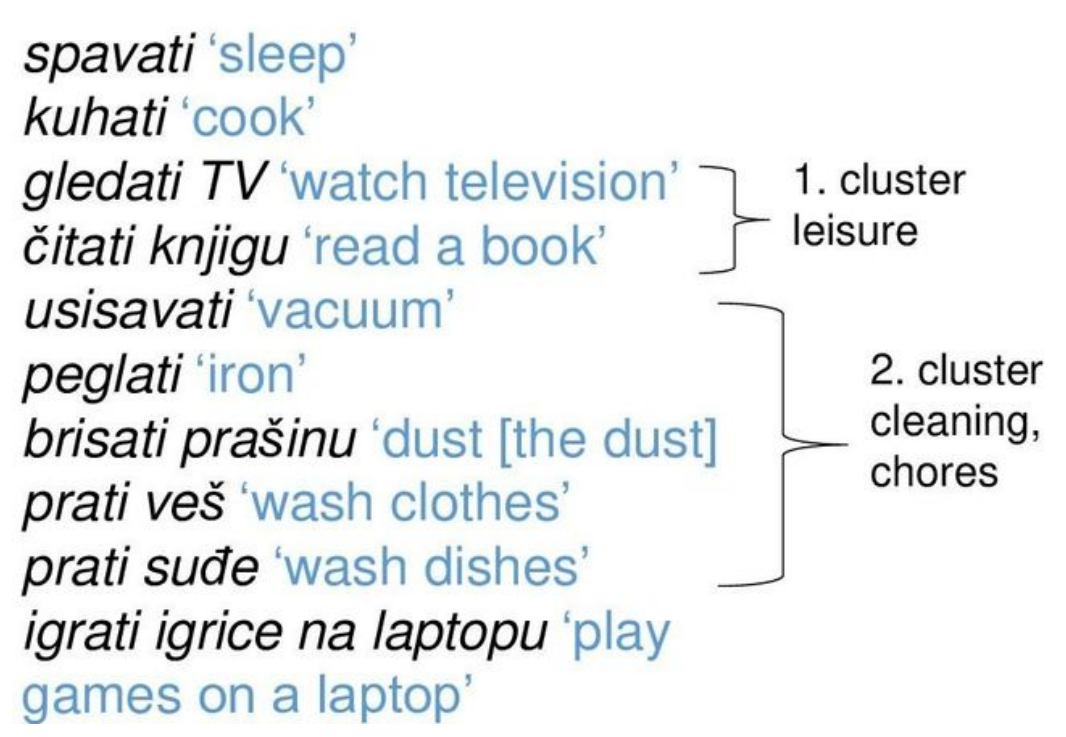

\section{Name as many words starting with $m$.}

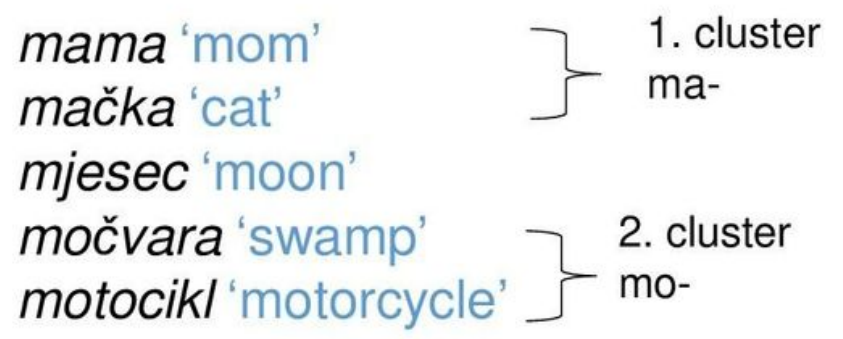

\section{Figure 3}

Transcripts of the first 15 seconds of the AF and LF tasks of one subject. In the AF transcript, cook, vacuum, iron, dust, and wash are both semantically and syntactically transitive verbs (although cook, vacuum, and iron were named in a syntactically intransitive manner by the subject, as per the lack of an expression of a direct object); watch and play are semantically intransitive but syntactically transitive verbs. Note that sleep is neither semantically nor (typically) syntactically transitive (but compare He slept two hours.). In conclusion, the subject produced seven syntactically transitive verbs and five semantically transitive verbs in the first 15 seconds of their output. 